WHOI-72-82

\title{
INVESTIGATION INTO THE FEASIBILITY OF DETECTING SALT FINGERS OPTICALLY
}

\author{
By \\ Carl Starck Albro \\ WOODS HOLE OCEANOGRAPHIC INSTITUTION \\ Woods Hole, Massachusetts 02543
}

August 1972

\begin{abstract}
TECHNICAL REPORT
Prepared for the Office of Naval Research under Contract N00014-66-C0241; NR 083-004.

Reproduction in whole or in part is permitted for any purpose of the United States Government. In citing this manuscript in a bibliography, the reference should be followed by the phrase: UNPUBLISHED MANUSCRIPT.

Approved for public release, distribution unIimited.
\end{abstract}

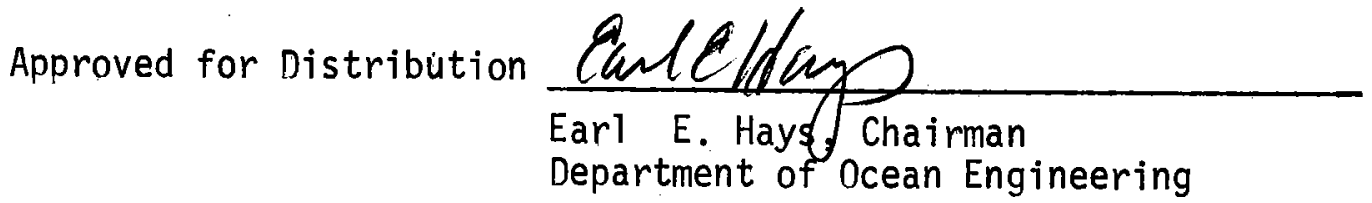




\section{INVESTIGATION INTO THE FEASIBILITY OF DETECTING \\ SALT FINGERS OPTICALLY}

by

CARL STARCK ALBRO

B.S.M.E., University of Massachusetts

(1970)

SUBMITTED IN PARTIAL FULFILLMENT OF THE REQUIREMENTS FOR THE DEGREES OF

OCEAN ENGINEER

at the

MASSACHUSETTS INSTITUTE OF TECHNOLOGY

and the

WOODS HOLE OCEANOGRAPHIC INSTITUTION

and

MASTER OF SCIENCE IN OCEAN ENGINEERING

at the

MASSACHUSETTS INSTITUTE OF TECHNOLOGY

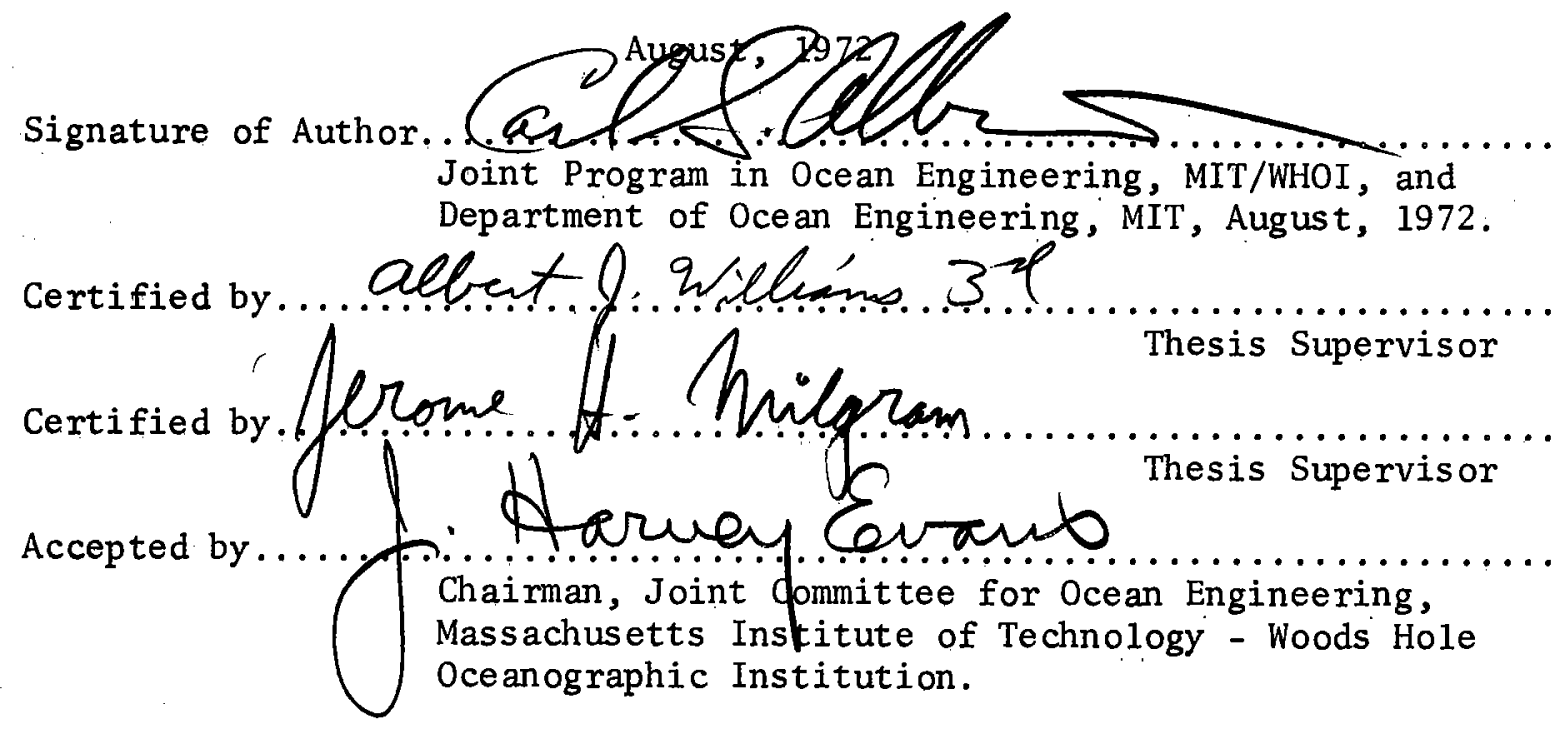




\section{INVESTIGATION INTO THE FEASIBILITY OF DETECTING \\ SALT FINGERS OPTICALLY}

by

CARL STARK ALBRO

Submitted to the Department of Ocean Engineering in partial fulfillment of the requirements for the degrees of Ocean Engineer and Master of Science in Ocean Engineering.

\section{$\underline{\text { ABSTRACT }}$}

During the last decade there has been an increasing interest in discovering the existance of salt fingering in the ocean. The purpose of this investigation was to determine the feasibility of optically detecting salt fingers.

Theoretical calculations were conducted on the angular deviation and displacement of parallel light rays propagating through an ordered salt finger model. It is assumed that salt fingers are square cells (one centimeter) with a checkerboard pattern of cells having high and low indices of refraction. The amplitude of index of refraction, above and below the overall average, was assumed to be between $5 \times 10^{-4}$ to $5 \times 10^{-6}$. From the computer work it was concluded that an optical method that detects displacement or intensity would have more promise of finding salt fingers in the ocean than an optical method that detects angular deviations.

From the computer results and experimental shadowgraph investigations conducted by others, it was concluded that a shadowgraph method is the most promising optical approach to use for detection of salt fingers. Depending on the strength of the salt fingers, the optimum distance between the fingers and the shadowgraph screen may be as far as one to three hundred meters to obtain a sharp image. To shorten this optical path a telescope-microscope lens system called a "shadowgraph shortener" was used.

Salt finger detection experiments were conducted in a large tank of salt water. An expanded laser beam ( 5 centimeters) was passed through the salt water and the "shadowgraph shortener" to fall on a ground glass screen which was photographed with a $16 \mathrm{~mm}$ movie camera. The weakest salt fingers detected had a salinity gradient of .02 parts per thousand per 6 centimeters. A survey was conducted on the salinity gradients in the Atlantic Ocean using Nansen bottle data from hydrographic stations. The larger salinity gradients found in parts per thousand per 50 meters were only one order of magnitude weaker than the experimental results.

An optical salt finger detector was designed using the same basic set-up as used in the experiments.

Thesis Supervisor: Albert J. Williams III

Title: Assistant Scientist at Woods Hole Oceanographic Institution

Thesis Supervisor: Jerome H. Milgram

Title: Associate Professor of Naval Architecture at Massachusetts Institute of Technology 


\section{ACKNOWLEDGEMENTS}

The advice and encouragement of many people contributed to this study. In particular I would like to thank the following persons:

Dr. Albert J. Williams III and Professor Jerome H. Milgram, who as thesis supervisors, provided sound technical advice and valuable criticism; Claude Ronne for his invaluable photographic assistance; and all the members of Graphic Arts for their patience and excellent work.

Also I would like to thank my wife, Donna, for her encouragement and patience. 
TABLE OF CONTENTS

\section{Page}

ABSTRACT. . . . . . . . . . . . . . . . . . . . . i ACKNOWLEDGEMENTS. . . . . . . . . . . . . . . . . . . . . . . . . .

TABLE OF CONTENTS . . . . . . . . . . . . . . . . . . . . . . . . . . . . . . . . . . . .

LIST OF ILLUSTRATIONS . . . . . . . . . . . . . . . . iv

I. INTRODUCTION, . . . . . . . . . . . . . . . . . . I

II. PREVIOUS INVESTIGATIONS OF SALT FINGER DETECTION. . . . . . . . 7

III. THEORETICAL CALCULATIONS OF OPTICAL PROPERTIES OF SALT FINGERS. . 14

IV. EXPERIMENTAL SET-UP AND PROCEDURE . . . . . . . . . . . . . . 32

V. RESULTS AND DISCUSSION. . . . . . . . . . . . . . . . . . . . . . . .

REFERENCES. . . . . . . . . . . . . . . . . . . . . . 42

APPENDIX A - COMPUTER FLOW CHART OF RAY TRACING PROGRAM . . . . . . . .44

APPENDIX B - OPTICAL SALT FINGER DETECTOR DESIGN. . . . . . . . . 47 


\section{LIST OF ILLUSTRATIONS}

Figure 1. Page

Figure 2, (a) Typical step and layer of salinity and temperature from Howe and Tait (1970). (b) Typical salinity and temperature profile from Cooper and Stomme1 (1970). . . . . 4

Figure 3. Salinity difference over 50 meters in parts per thousand. . . 5

Figure 4. Schematic of multislit schlieren. . . . . . . . . . . . 7

Figure 5. Typical example of a recorded run when sugar-salt fingers are present . . . . . . . . . . . . . . 9

Figure 6. Schematic diagram of acoustic detector. . . . . . . . . 10

Figure 7. Schematic set-up of Charles Eriksen's shadowgraph experiments ............. . . . . . . . . . 11

Figure 8. A vertical shadowgraph of highly oriented sugar-salt fingers......................... . 12

Figure 9. Index of refraction contours of ordered salt fingers. . . . 15

Figure 10. Total index of refraction gradient perpendicular to the light ray ....................... 17

Figure 11. Geometric representations of items. . . . . . . . . . . 18

Figure 12. Angular deviations of light rays for the initial angles of $15^{\circ}, 30^{\circ}$, and $45^{\circ}$................. 19

Figure 13. Angular deviations of light rays for the initial angles

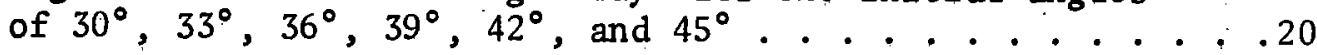

Figure 14. Maximum angular deviations of light rays of initial ang les from $0^{\circ}$ to $45^{\circ}$..................... . . 22

Figure 15. Displacement of light rays for the initial angles

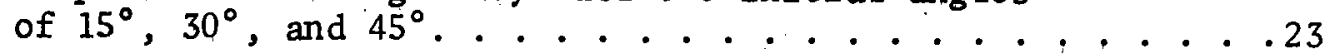

Figure 16. Maximum displacement of light rays for initial angles

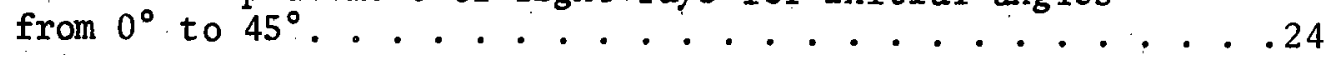

Figure 17, Ray tracing of light through ordered salt fingers . . . . . 25

Figure 18. Intensity fluctuation versus light ray path length. . . . . 26

Figure 19. Laser beam expander . . . . . . . . . . . . . . . . 27

Figure 20. Object distance of a shadowgraph. . . . . . . . . . . . 28 
Figure 21. Shadowgraph shorteners. Page

Figure 22. Schematic of experimental set-up. . . . . . . . . . . .33

Figure 23. Shadowgraph results . . . . . . . . . . . . . . . 37

Figure 24. Shadowgraph results . . . . . . . . . . . . . . . 38

Figure 25. Geometric representations of some of the terms in the computer program. . . . . . . . . . . . . . . 46

Figure 26. Endcap clamping of optical salt finger detector . . . . . . 49

Figure 27. Three possible configurations of the optical salt finger detector .. . . . . . . . . . . . . . 50

Figure 28. Photograph - the optical equipment in the box channel at tached to the flat end plate. . . . . . . . . . . 53

Table 1 Calculations of image sizes for various cell sizes and angles of deviation...................... . . . . 


\section{INTRODUCTION}

In the last sixteen years there has been increasing interest in discovering the existence of salt fingering in the ocean. In 1956, Stommel et al. wrote a short paper describing a perpetual salt fountain. A salt fountain can occur in a two layer system of hot, salty water over cold, less salty water in which the hot, salty water is less dense than the cold water, thus being gravitationally stable. If a small tube is put into the tank allowing only the water from the lower layer to enter the tube, the cold water in the tube being surrounded by hot water is heated up causing the water in the tube to become less dense than the surrounding water. Therefore, the fresh water in the tube rises which in turn brings more fresh water up the tube to continue the process.

The success of the above fountain is due to the diffusion of heat without the diffusion of salt, but Stern (1960) noted that since the molecular diffusivity of heat $\left(K_{T}=1.5 \times 10^{-3} \mathrm{~cm}^{2} \mathrm{sec}^{-1}\right)$ is about two orders of magnitude larger than the molecular diffusivity of salt $\left(K_{S}=1.3 \times 10^{-5}\right.$ $\mathrm{cm}^{2} \mathrm{sec}^{-1}$ for salinity of $35 \%$ at $20^{\circ} \mathrm{C}$ ), the tube is not needed in order to have a fountain. If a small parcel of water is displaced up or down, it will gain or lose heat faster than it gains or loses salt, thus the body of water continues to rise or sink. After a while there are numerous little salt fountains which are called salt fingers (see Figure 1) flowing in opposite directions .

If salt fingers exist in the ocean, they will be an efficient mechanism for the vertical transport of heat and salt (i.e. more effective method than molecular diffusion of salt and heat, Turner, 1967). Stern (1969) has concluded from theoretical calculations that salt fingers might be a possible 


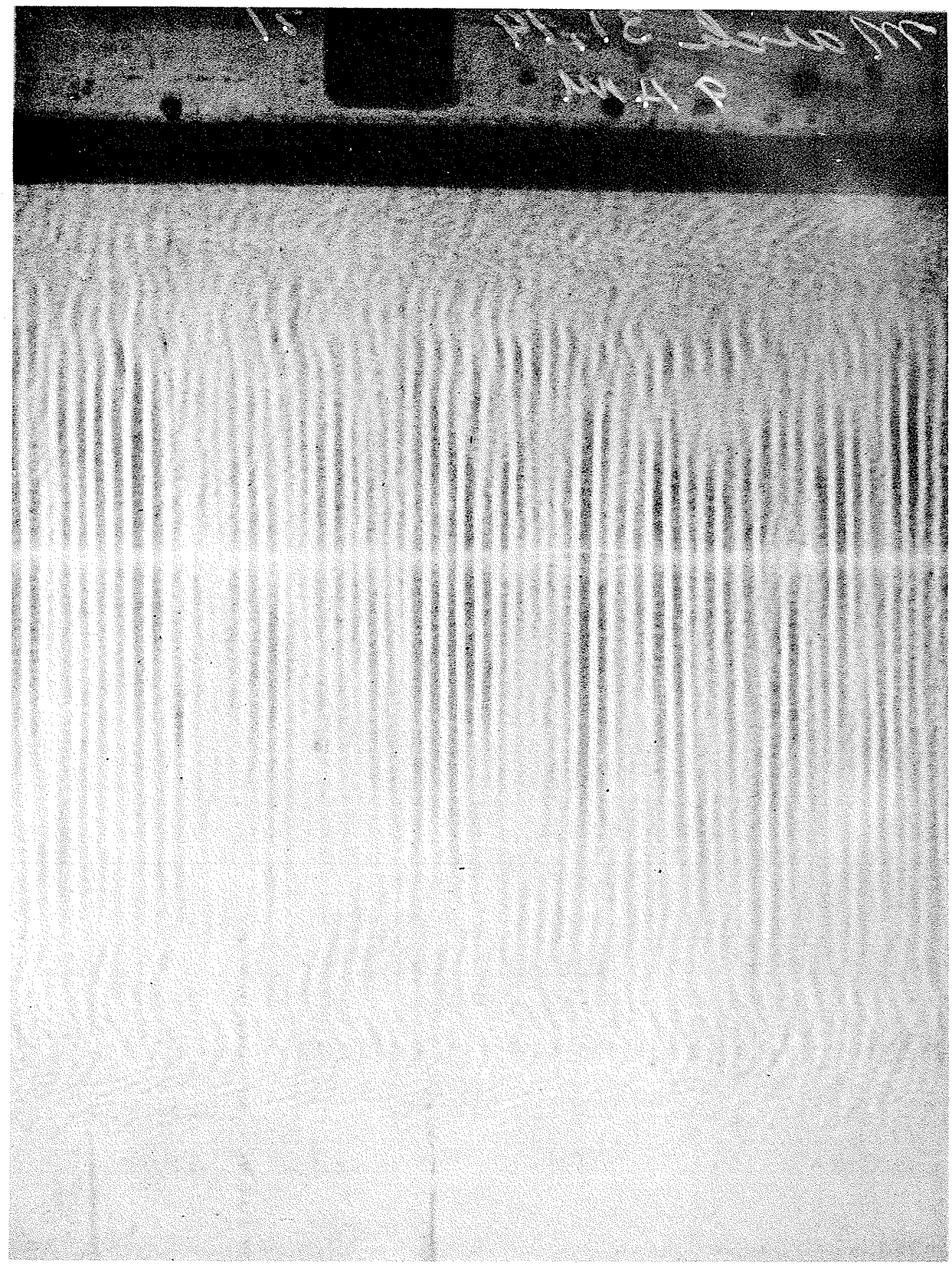

Figure 1. Shadowograph view of salt fingers. Photograph was taken by Claude Ronne for Albert J. Williams III. 
energy source for internal waves. Salt fingers may also serve as a dilution mechanism for a submerged cloud of sewage effluent (Fischer, 1971).

Howe and Tait (1970) and Cooper and Stommel (1968) have reported step-like profiles of temperature and salinity in the ocean which is a favorable condition for salt fingering to occur. Howe and Tait (1970) have found these profiles near the Mediterranean outflow in the Atlantic with an STD probe. These steps and layers were found between the depths of 1300 meters and 1500 meters. Figure 2a shows the various parameters of these steps. Cooper and Stommel (1968) have reported finding similar kinds of profiles near Bermuda (see Figure $2 b$ ).

From experimental investigations conducted by Eriksen (1971) and the author, it has been observed that salt fingers occupy a region where linear gradients of salinity and temperature occur. Using the average salinity gradient as an indication of the probability of salt fingering (in the absence of any additional information), a contour map of the At lantic's maximum difference in salinity over a 50 meter interval was made. Only the salt fingersing case of salty water above fresh water was indicated (see Figure 3). The data for the above map comes from Nansen bottles at hydrographic stations of which Fuglister (1960) and Metcalf and Stalcup (1969) are the main sources. The dots in Figure 3 represent these hydrographic stations. The hydrographic data considered was further restricted to the depth range of 100 meters to 1000 meters below the ocean surface with the average depth between two bottles greater than 140 meters below the surface :

Ideally one would like to detect salt fingers in the ocean by recording the direct ocean parameters (temperature, salinity, density and vertical 
(a)

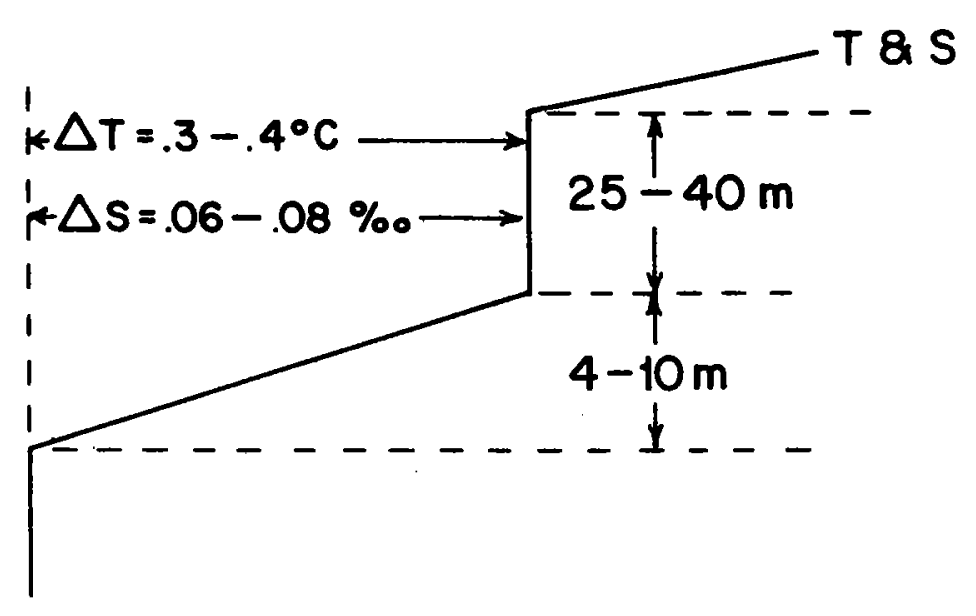

(b)

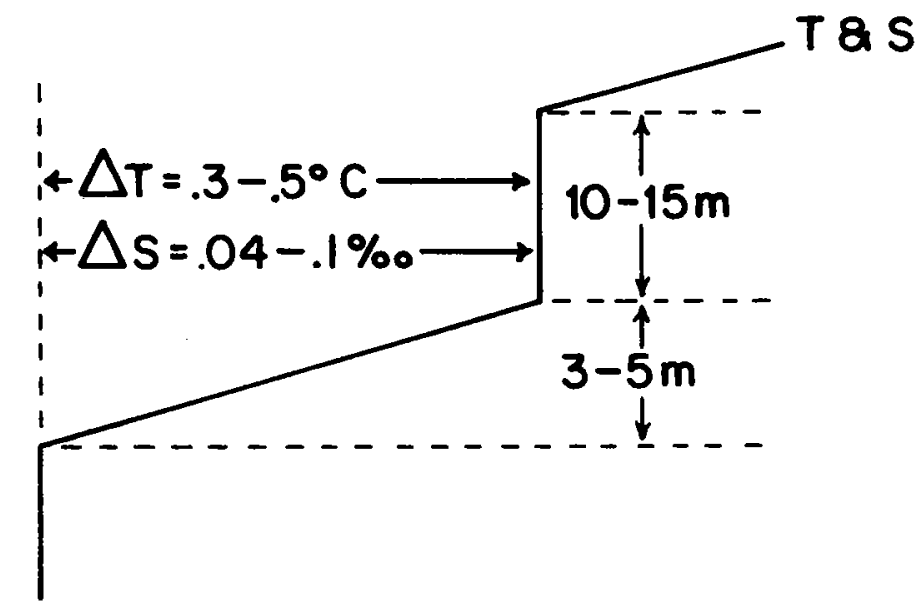

Figure 2. (a) Typical step and layer of salinity and temperature from Howe and Tait (1970). (b) Typical salinity and temperature profile from Cooper and Stomme1 (1970). 


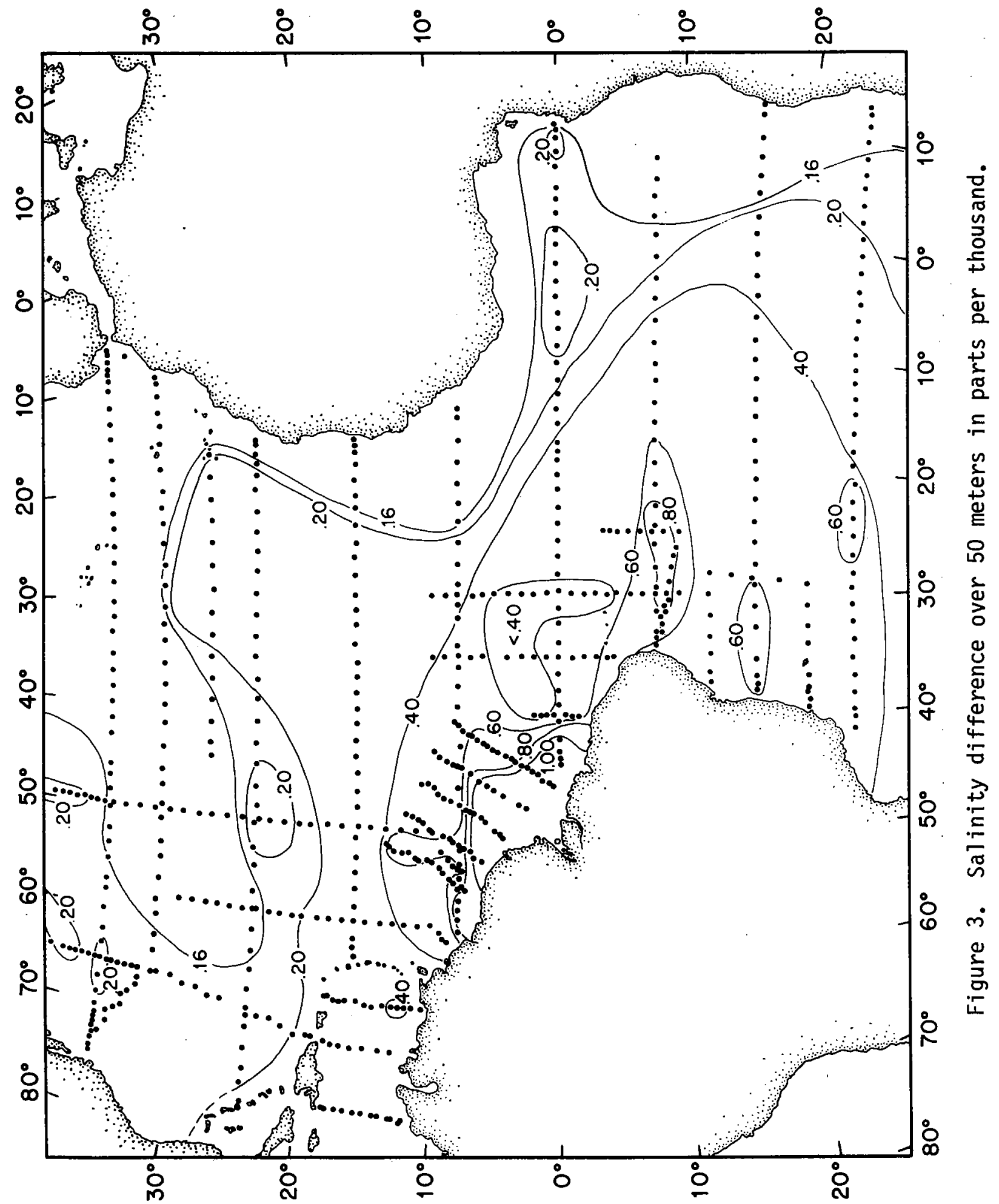


velocity), but the variations in these parameters are quite small. A more reasonable approach to use in detecting salt fingers is to rely upon the characteristic effects of indirect parameters, such as index of refraction, electrical conductivity, speed of energy propagation, and attenuation of light or sound. Another property of salt fingers which should be useful in detecting salt fingers is that they have at least a short ordering of coherent and symmetrical cell structures. The above property will cause any energy that propagates horizontally through salt fingers to be diffracted, refracted and scattered. The propagation of energy through several salt fingers will produce a semi-random fluctuation of the signal which will be statistically detectable.

The purpose of this investigation is to determine the feasability of detecting salt fingers optically. The following is a study of previous investigations of salt finger detection, theoretical calculations of optical properties of salt fingers and experimental work resulting from the theoretical calculations. 
I I. PREVIOUS INVESTIGATIONS OF SALT FINGER DETECTION

Several investigations have been conducted or are being conducted using some of the above-mentioned properties for detecting salt fingers in the ocean. Albro and Curtis (1971) conducted an experiment using a modified eclipsed schlieren technique. They passed an expanded laser beam through a Ronchi ruling, a tank of sugar-salt fingers, and a second Ronchi ruling onto a photoconductivity cell [Sugar-salt fingers are produced by carefully pouring a layer of aqueous sugar solution over a layer of aqueous salt solution where the two layers are gravitationally stable (Stern and Turner, 1969)]. The second Ronchi ruling eclipses the light that passes through the first Ronchi ruling (see Figure 4).

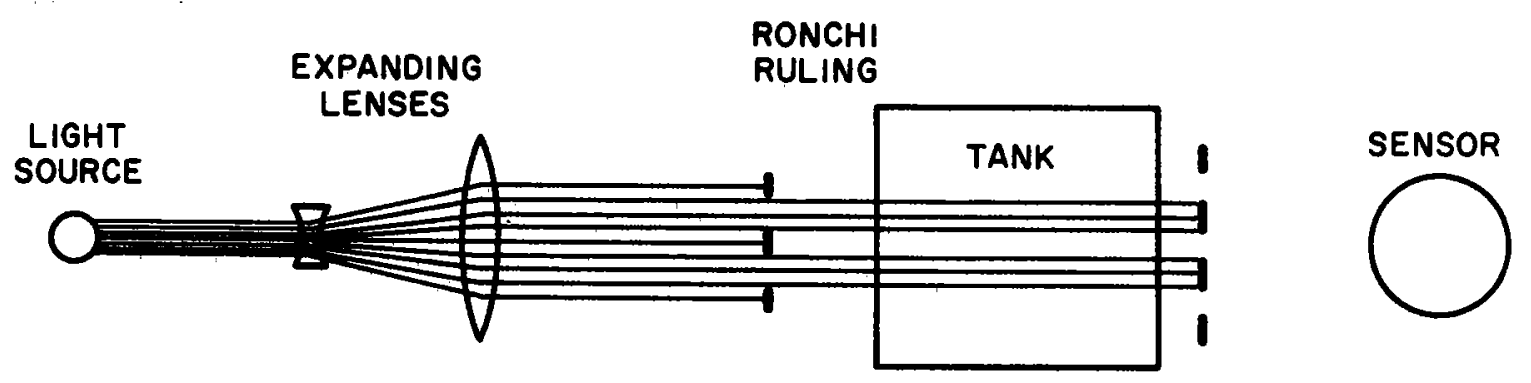

NO SALT FINGERS PRESENT

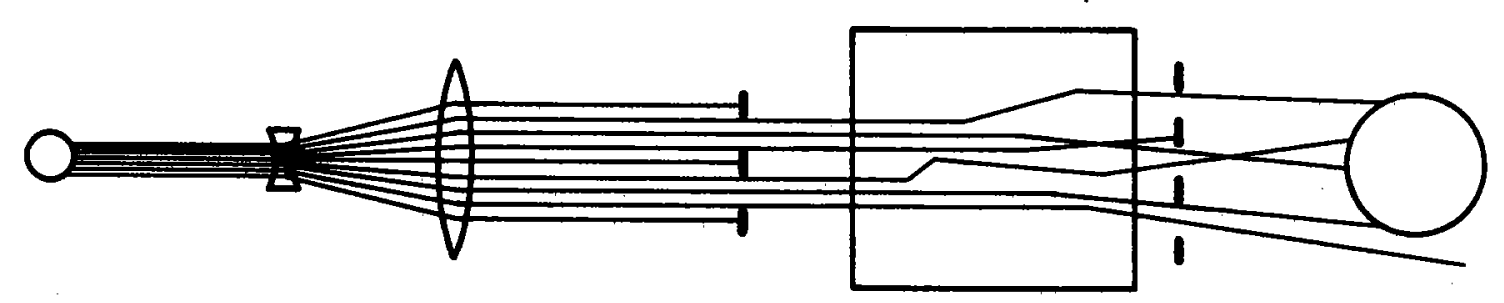

SALT FINGERS PRESENT

Figure 4. Schematic of multislit Schlieren.

If sugar-salt fingers exist in the tank, the differences in the index of refraction between the fingers causes the light to be refracted, thus allowing some of the light to pass through the second Ronchi ruling and fall 
on the photoconductivity ce11. The photoconductivity cell was put in series with a resistor and a battery in order to produce a voltage signal across the cell since its resistance is a function of light intensity. The voltage signal across the cell.was recorded on a Sanborn, hot pen, paper chart, recorder.

From the above investigation, it was found to be difficult to detect any change in light intensity as the salt fingers developed if the laser beam passed through only one region of the tank of sugar-salt fingers. If the tank was translated across the beam, no significant fluctuations in light intensity were noticed for undisturbed and turbulent sea water while bubbles on the wall of the tank produced an irregular fluctuating signal, and sugar-salt fingers produced a somewhat regular sinusoidal fluctuation in signal (see Figure 5). The investigators knew when they had sugarsalt fingers since they were strong enough to be seen with an unaided eye. Kim et al. (1971) conducted experiments using an ultrasonic pulseecho technique for detecting sugar-salt fingers (see Figure 6). A small transducer capable of producing sonic frequencies from $800 \mathrm{KHz}$ to $45 \mathrm{MHz}$ transmitted a horizontal beam of sound which was returned by a reflector and detected by the transducer. The attenuation of the beam echo was determined. The investigators found that there was an attenuation 1 oss of about $1.4 \mathrm{~dB} / \mathrm{cm}$ (in the 25 to $42 \mathrm{MHz}$ range) in the sugar-salt finger interfacd as compared to the regions above and below the interface. The investigators believe that the loss was due to some type of scattering.

In the summer of 1971, Charles Eriksen investigated the use of a shadowgraph method for detecting salt fingers while working at Woods Hole Oceanographic Institution on a fellowship. He used a laser beam which was 
$-9-$

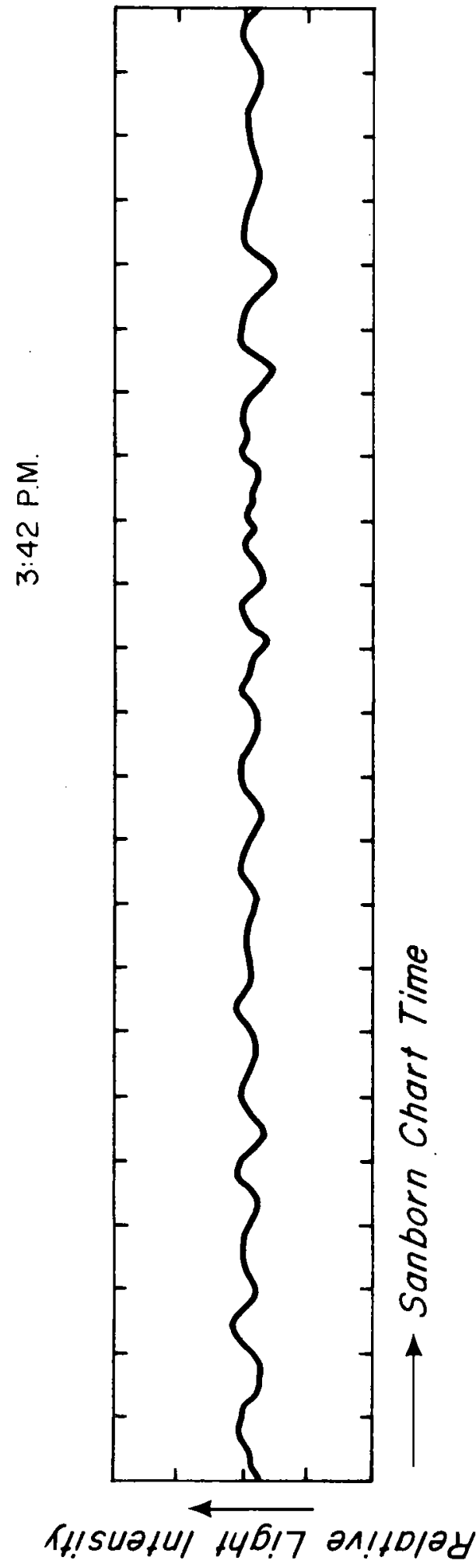

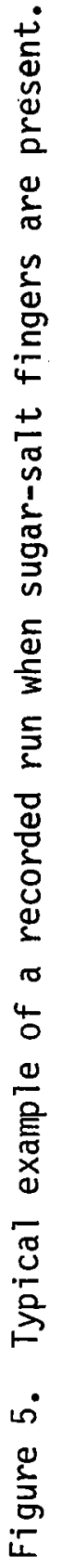




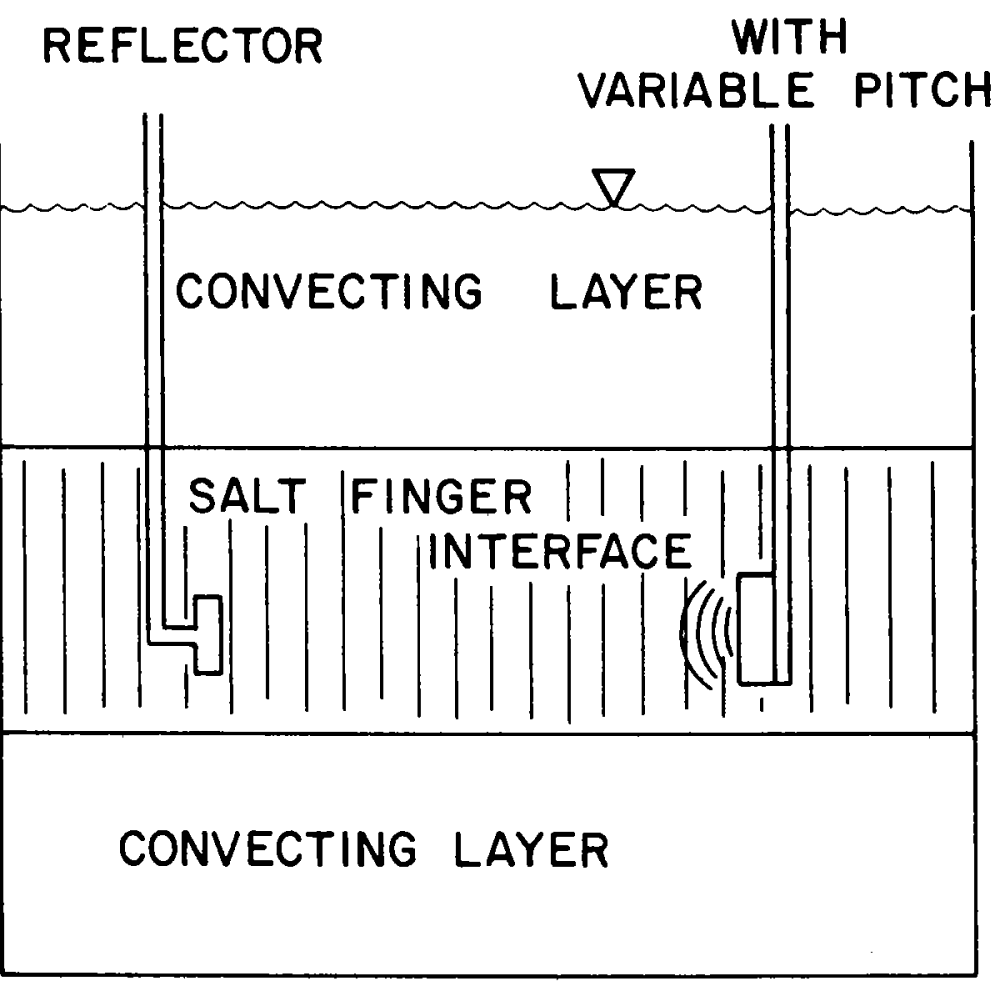

Figure 6. Schematic diagram of acoustic detector. Redrawn from Kim et al. 1971 . 
spatially filtered, expanded to five centimeters, and collimated as his shadowgraph light source. The beam was reflected down one periscope, through about eighteeen inches of sea water, up a second periscope onto a screen three meters away to form a shadowgraph image (see Figure 7).

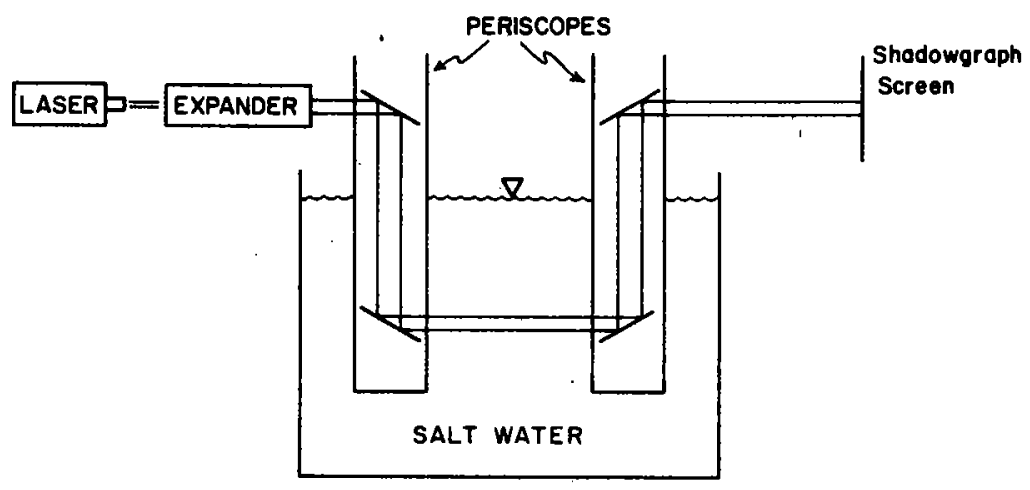

Figure 7. Schematic set-up of Charles Eriksen's shadowgraph experiments.

Albert J. Williams III (private communication) found that small tank size where the more narrow tank dimension is only about one order of magnitude larger than the width of a salt finger causes a high order of orientation of the fingers along the long side (see Figure 8). Therefore, Eriksen (1971) used a large tank where most of the volume was far from the walls. This reduced the above-mentioned effect so that the experiment was more like a real ocean situation. The investigator obtained shadowgraphs of salt fingers in which the salinity gradient was about 500 times stronger than that expected in the ocean.

Bruce Magne11 (private communication) is using conductivity cells to search for salt fingers. The investigator has mounted a conductivity sensor and temperature sensor on the leading portion of a towed fish with two 




$\frac{5}{0}$
$\frac{0}{5}$
0
$+\frac{1}{0}$
$\frac{9}{1}$

$\frac{n}{2}$

$\pm$

距

1曰

ชัญ

的.

导: 宁

胥

है

过

굴

它分

40

등응

중

홍ㅁำ

음

ज

రิ

正学

क

$<\frac{\pi}{3}$

$\infty$

克 
thermocouple heads and conductivity cells about 30 centimeters apart from each other behind the front sensor. The front sensors measure individual salt fingers while the back sensors are used to get the temperature and salinity gradients. The apparatus is towed at various depths and various speeds. If the instrument goes through a region of salt fingers, it is hoped that the conductivity cell will sense an alternating change in conductivity as it passes through each individual salt finger. The investigator has not done any laboratory detection of salt fingers, but he has put his instrument through a salt ring (similar to a smoke ring) which had a .003 difference in salinity from the surrounding water, and his sensors detected this ring. Recent experiments near Bermuda (June, 1972) give a strong indication of fingers with a spacing of $2 \mathrm{~cm}$. 
III: THEORETICAL CALCULATIONS OF OPTICAL PROPERTIES OF SALT FINGERS

Stem (1970) conducted a theoretical study on the light intensity fluctuations in traversing salt fingers using a random walk model for a ray path. He used a statistical approach assuming that salt fingers have a short range of ordering, i.e. each sinking finger is surrounded by four rising fingers of lower density. The difference in density causes a difference in the index of refraction between fingers. As light passes through these fingers it is refracted at each salt finger interface, thus changing the overall light intensity field of a light beam. From this study, Stem concluded that a micro-optical technique in conjunction with an STD probe would be a promising method of detecting salt fingers in the ocean.

From other investigators such as Albert J. Williams III (private communication), it is believed that salt fingers will exhibit a higher order of coherence than assumed by Stern, i.e. the salt fingers will be in clusters of square cells (say) at least ten cells square. To get some idea of the amount of refraction and deviation of light rays through ordered salt fingers, a computer ray tracing program was set up.

From several laboratory investigations of salt fingers and sugar-salt fingers, it has been determined that the fingers are made up of square cells with alternating high and low index of refraction (Shirtcliffe and Turner, 1970). Figure 9 shows the contours of index of refraction of a salt finger mode1.

The contours of index of refraction were determined from the following equation,

$$
\mathrm{n}=\mathrm{n}_{\mathrm{o}}+\Delta \mathrm{n} \cos \frac{\mathrm{x} \pi}{\mathrm{a}} \cos \frac{\mathrm{y} \pi}{\mathrm{a}}
$$




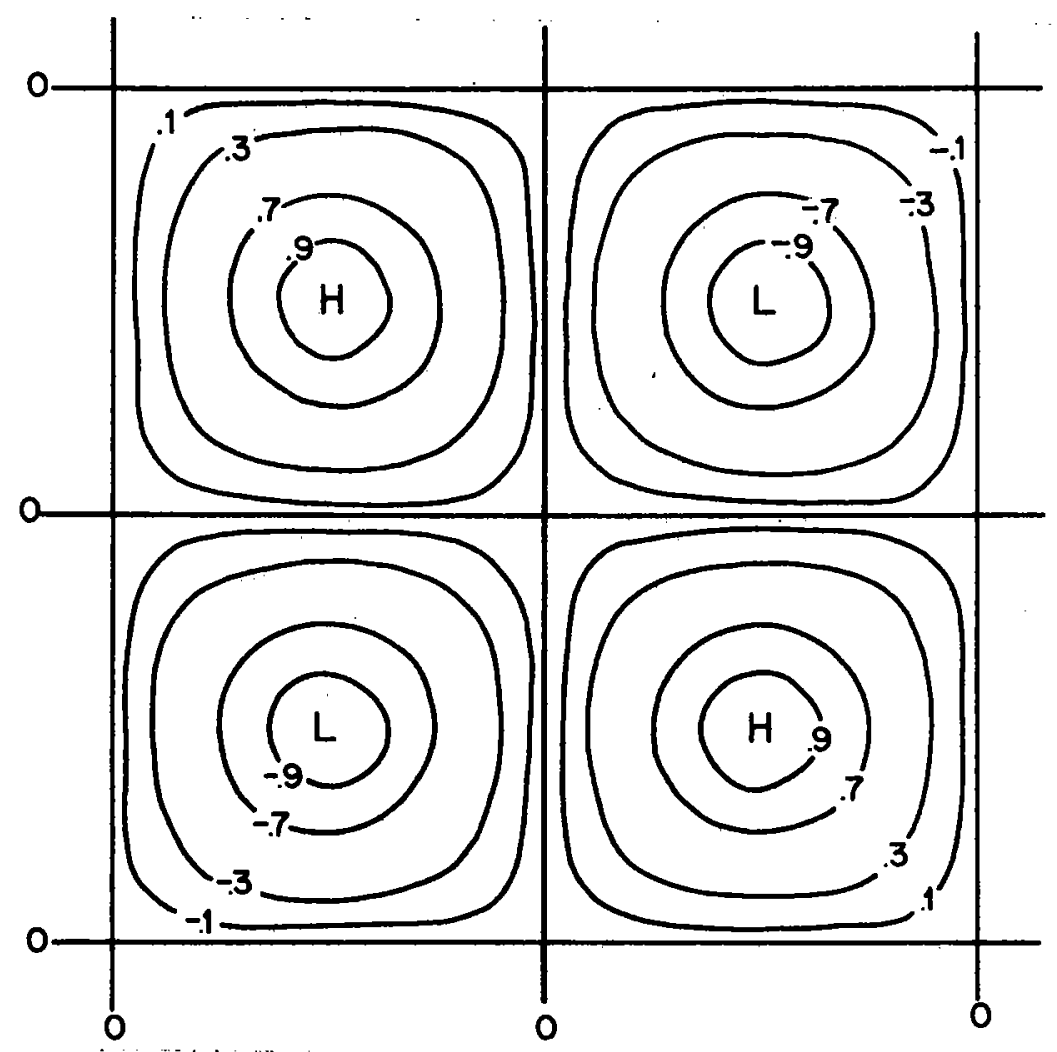

Figure 9. Index of refraction contours of ordered salt fingers.

where $\mathrm{n}$ is the index of refraction,

$\mathrm{n}_{0}$ is the average index of refraction

$\Delta \mathrm{n}$ is the amplitude of the index of refraction variation

a is the side dimension of a salt finger cell, and

$x$ and $y$ are coordinates with the origin in the center of a cell of high index of refraction

Light rays bend in a varying index of refraction field according to the following equation,

$$
\frac{d \theta}{d p}=\frac{1}{n}-\frac{\partial n}{\partial q}
$$

where $\theta$ is the angle of deviation

$p$ is the direction of the light ray, and

$\mathrm{q}$ is the distance perpendicular to the light ray path. 
The total angle of deviation over a path length would be

$$
\theta=\int_{2}^{1} \mathrm{~d} \theta
$$

Changing to the integral over path length and substituting equation 2 into 3, we obtain

$$
\theta=\int_{2}^{1} \frac{d \theta}{d p} d p=\int_{2}^{1} \frac{1 \partial n}{n \partial q} d p
$$

Since salt fingers have a two-dimensional index of refraction gradient, the gradients are projected on a line perpendicular to the light ray and added or subtracted where appropriate (see Figure 10).

From Figure 10, we obtain

$$
\mathrm{R}=\frac{\partial \mathrm{n}}{\partial \mathrm{x}} \sin \phi-\frac{\partial \mathrm{n}}{\partial \mathrm{y}} \cos \phi
$$

Equation 4 can now be rewritten in a form that the computer can use,

$$
\theta=\frac{\mathrm{dp}}{\mathrm{n}} \stackrel{\Sigma}{\mathrm{i}}_{\mathrm{N}}^{\mathrm{R}} \mathrm{R}_{\mathrm{i}}
$$

(Appendix A is a flow chart of the computer program used).

It has been estimated that the salt finger cell size is of the order of one centimeter (Stern, 1969). The amplitude of index of refraction can be determined from the following equation,

$$
\Delta \mathrm{n}=\eta_{\mathrm{s}} \Delta \mathrm{s}-\eta_{\mathrm{T}} \Delta \mathrm{T}
$$

where $\eta_{s}$ is the change of index of refraction versus salinity,

$\eta_{T}$ is the change of index of refraction versus temperature, and $\Delta S, \Delta T$ are the differences in salinity and temperature, respectively. If we assume that we have sea water at a temperature of $15^{\circ} \mathrm{C}$ and a salinity of $35 \%$, we get from the Handbook of Chemistry and Physics the following values: $\eta_{S}=1.8 \times 10^{-4} / \%$ and $\eta_{T}=-0.84 \times 10^{-4} /{ }^{\circ} \mathrm{C}$. Using these values with a temperature difference of $0.3^{\circ} \mathrm{C}$ and a salinity difference of $0.1^{\circ} / 00$, 


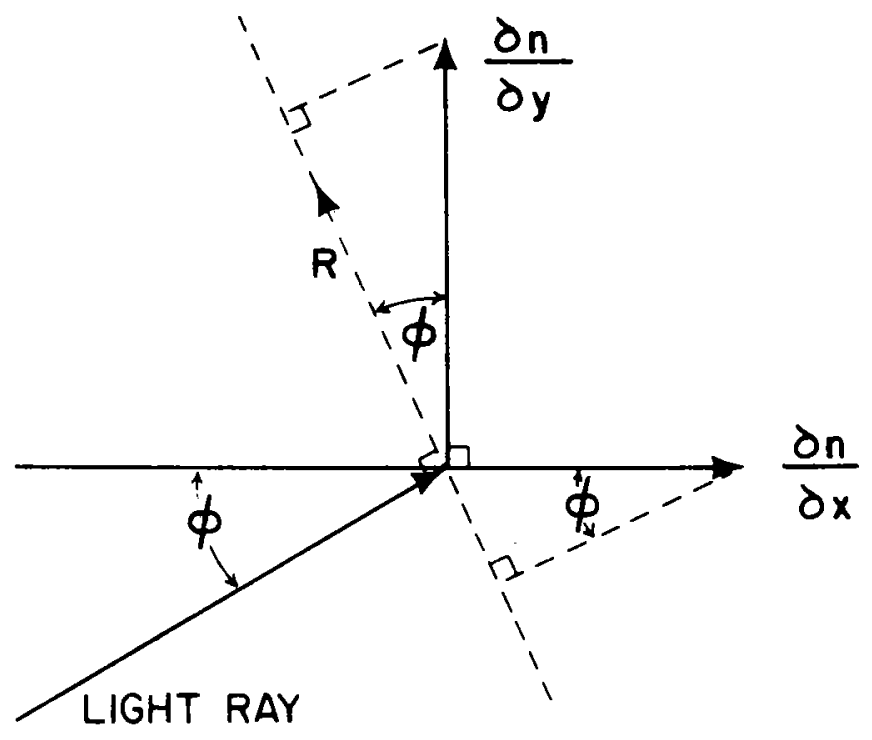

$$
R=\frac{\partial n}{\partial x} \sin \phi-\frac{\partial n}{\partial y} \cos \phi
$$

Where $R$ is the total index of refraction gradient perpendicular to the light ray.

Figure 10. Total index of refraction gradient perpendicular to the light ray. 
we obtain an amplitude of index of refraction of $7 \times 10^{-6}$. The minimum amplitude of index of refraction selected for the computer work was $5 \times 10^{-6}$ and the maximum was $5 \times 10^{-4}$. In all of the ray tracing results, it was assumed that the average index of refraction was 1.344. Figure 11 gives the geometric representation of terms used in the following Figures 12 through 18.

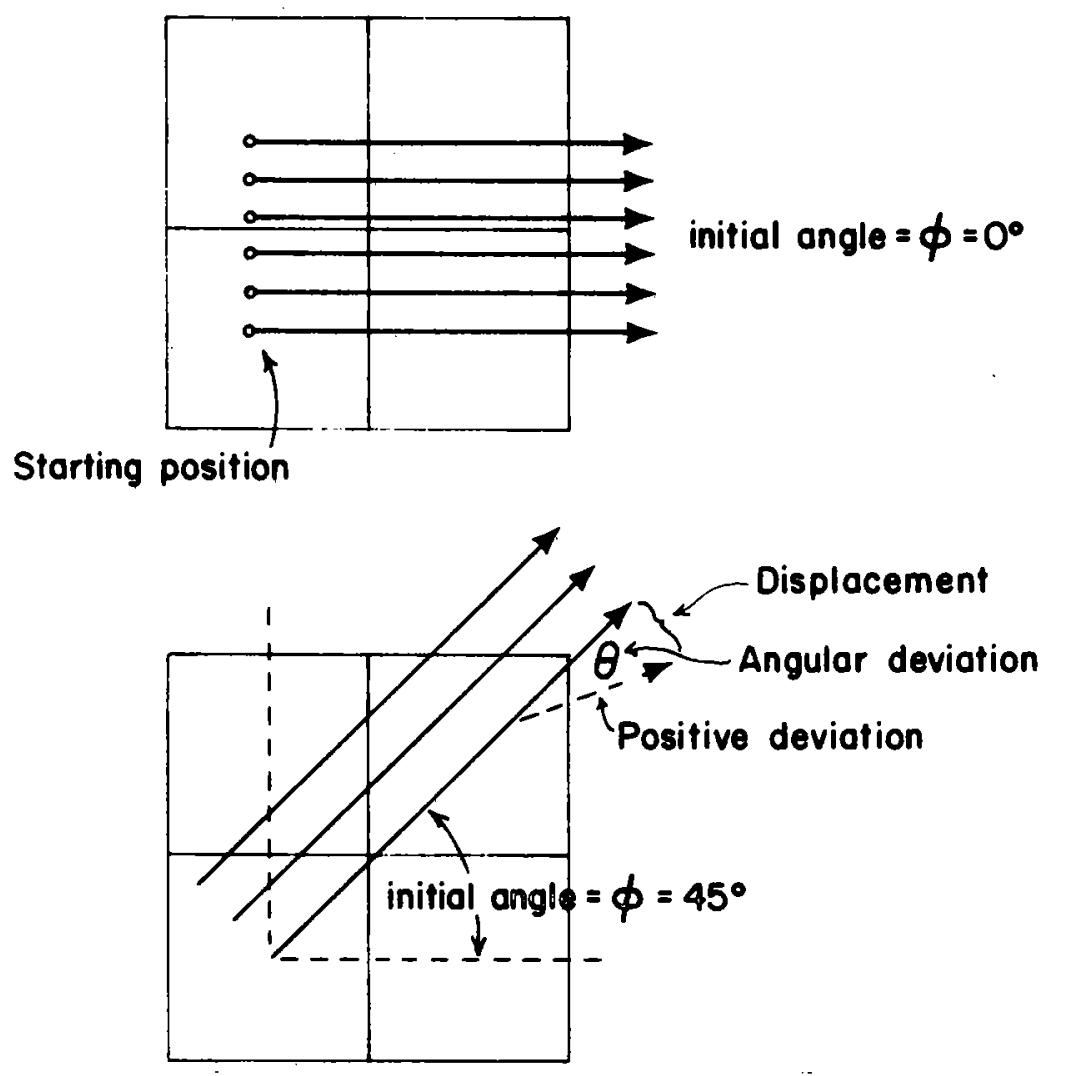

Figure 11. Geometric representations of terms.

Figure 12 shows the angular deviation of light rays versus starting position for three initial angles. It can be seen from this figure that there is a considerable difference in angular deviation of light rays starting at 30 degrees and 45 degrees. Figure 13 has initial angles going from 30 degrees to 45 degress in intervals of three degrees. It can be seen that the maximum angular deviation for initial angle 36 degrees is less than 


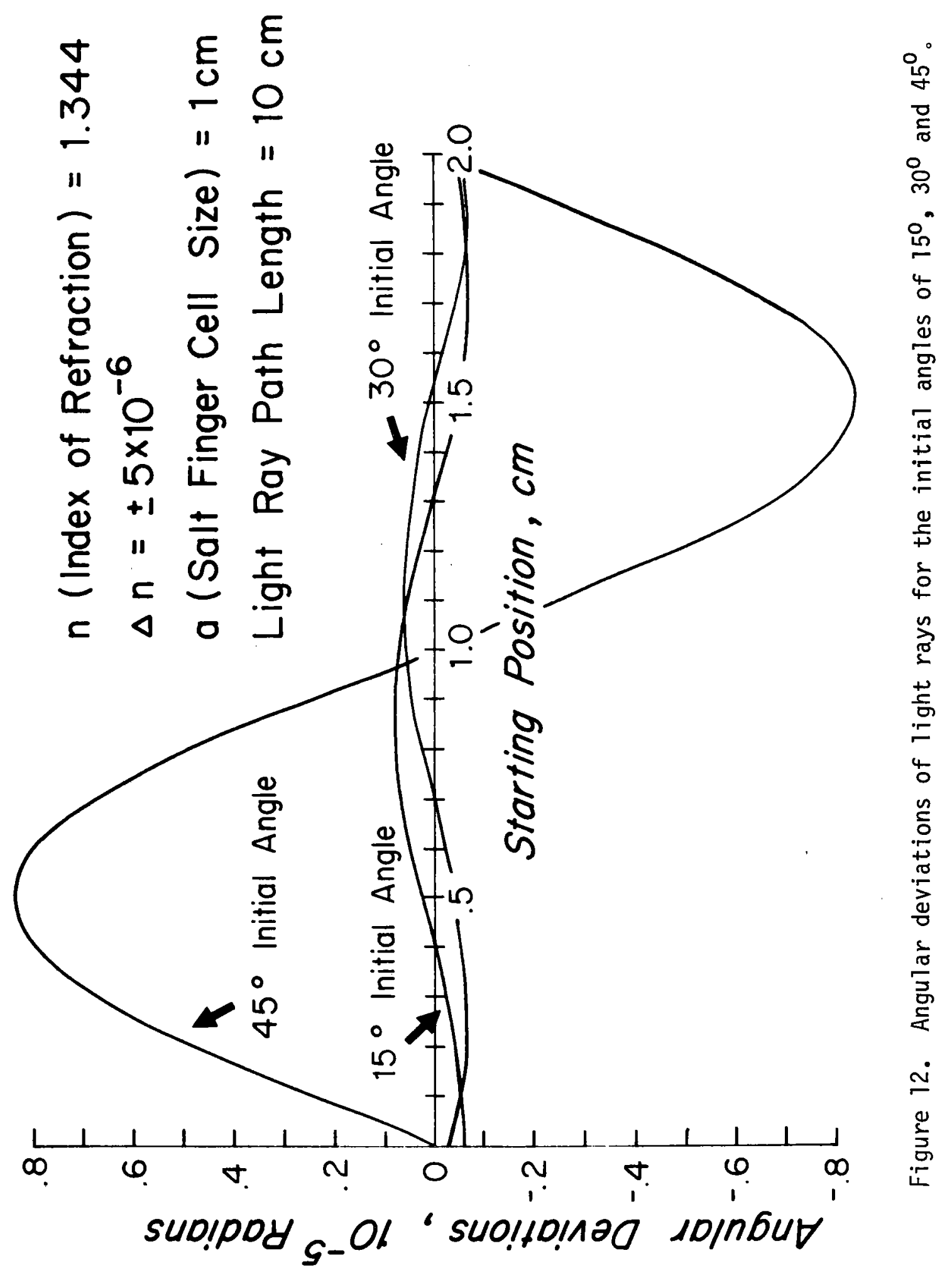




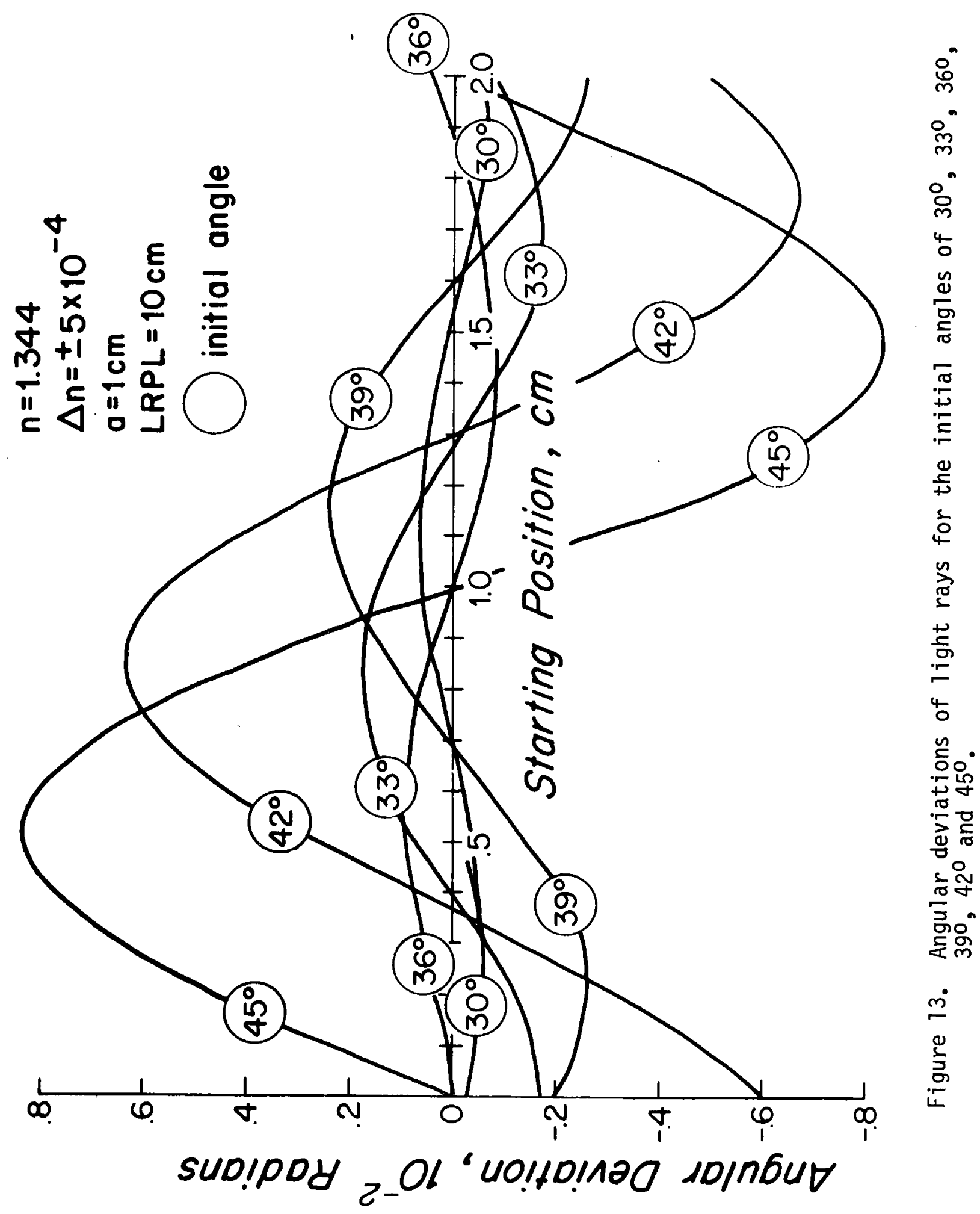


that of initial angle 33 degrees. Figure 14 gives us a more detailed relationship between the initial angle and maximum angular deviation.

Figure 15 shows the displacements of light rays perpendicular to the undeviated light path versus starting position for different initial angles. Figure 16 shows the maximum displacement versus initial angle. From a comparison between Figures 14 and 16, it can be concluded that an optical method that detects displacement or intensity would have more promise of finding salt fingers in the ocean than an optical method that detects angular deviations. To get an idea of the concentration of light by salt fingers, a computer ray tracing was made of light rays going through about thirty ordered salt fingers (see Figure 17). Out of the computer work it was also found that as the light beam passes through ordered salt fingers, the intensity fluctuation changes as the light path length increases (see Figure 18).

From the computer results and experimental shadowgraph work conducted by Albert J. Williams III (private communication) and Eriksen (1971), it is the author's conclusion that a shadowgraph method is the most promising optical approach to use for detection of salt fingers. As learned from Eriksen's investigation, an expanded laser beam (see Figure 19) is a good source of parallel light. It is important to have adjacent light rays parallel to each other so that the signal (refraction by salt fingers) to noise (local variations in ray direction) ratio be kept to a maximum. Thus, if retraction is expected to be no larger than 25 pradians, local collimation of the beam must be good to $10 \mu$ radians .

A shadowgraph is formed at some optimum distance from fingers. If we assume a salt finger cell size of 10 millimeters and an angle of deviation of $2.5 \times 10^{-5}$ radian, Figure 20 and the following equation, 


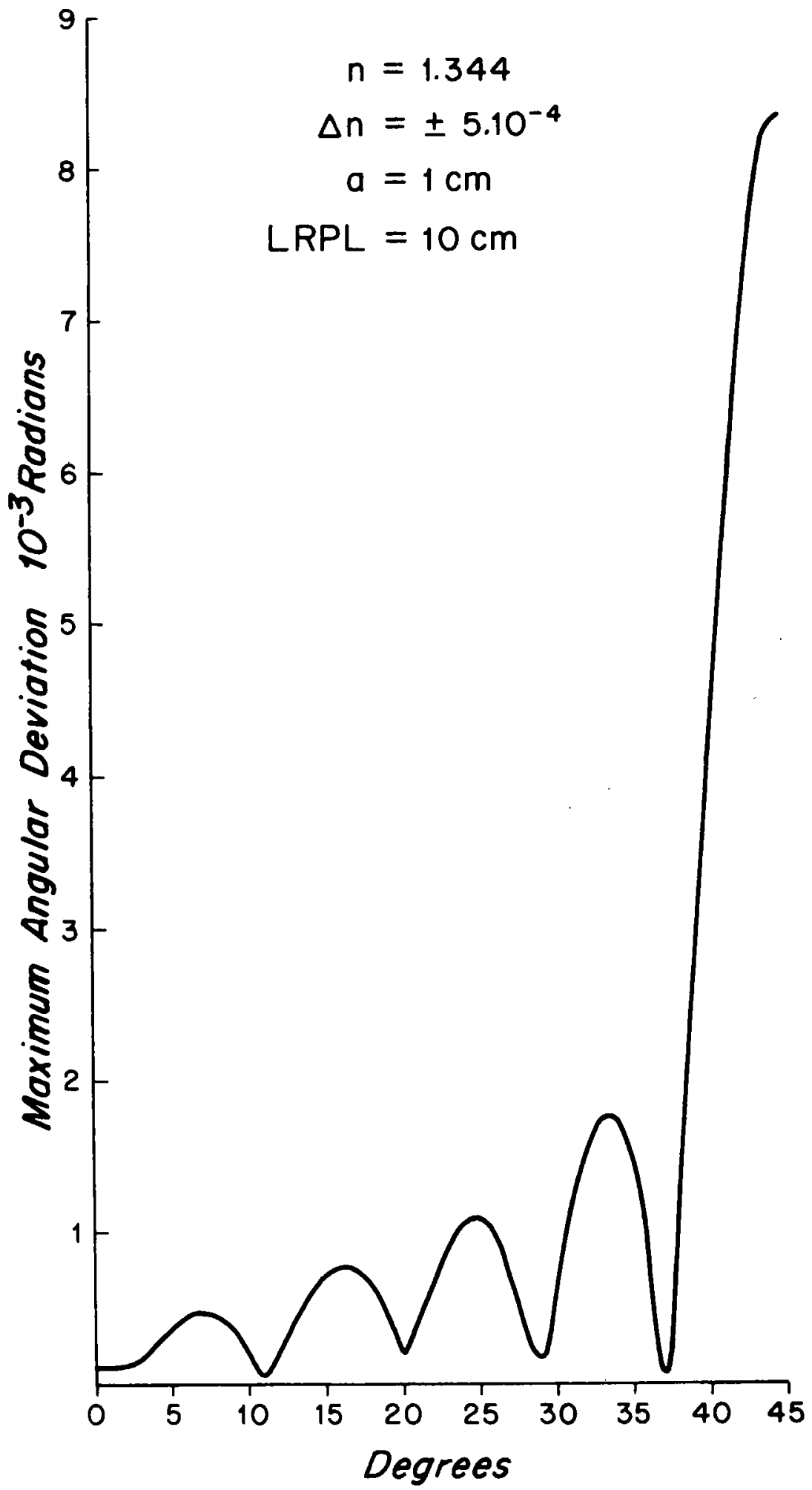

Figure 14. Maximum angular deviations of light rays of initial angles from $0^{\circ}$ to $45^{\circ}$. 


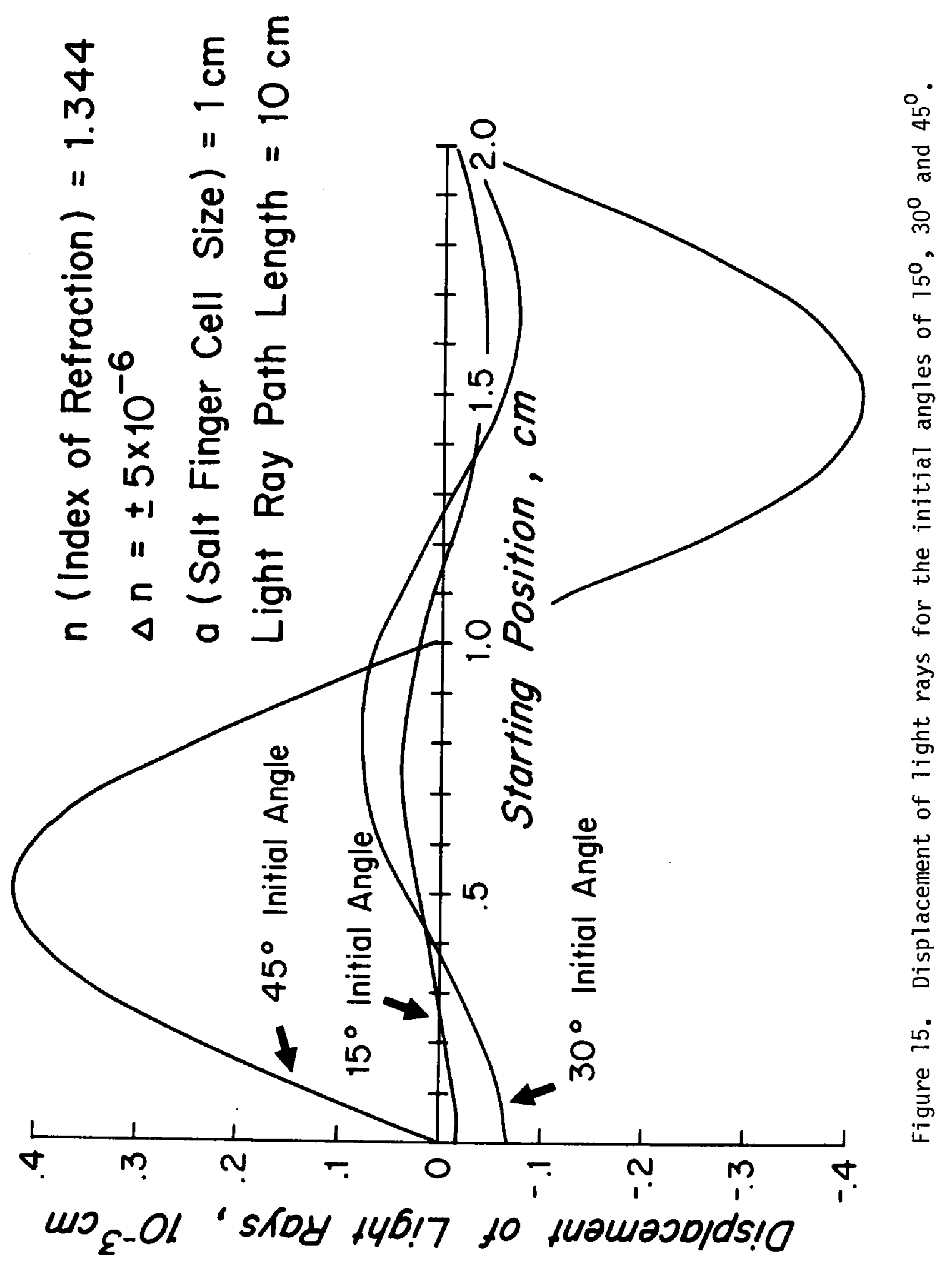




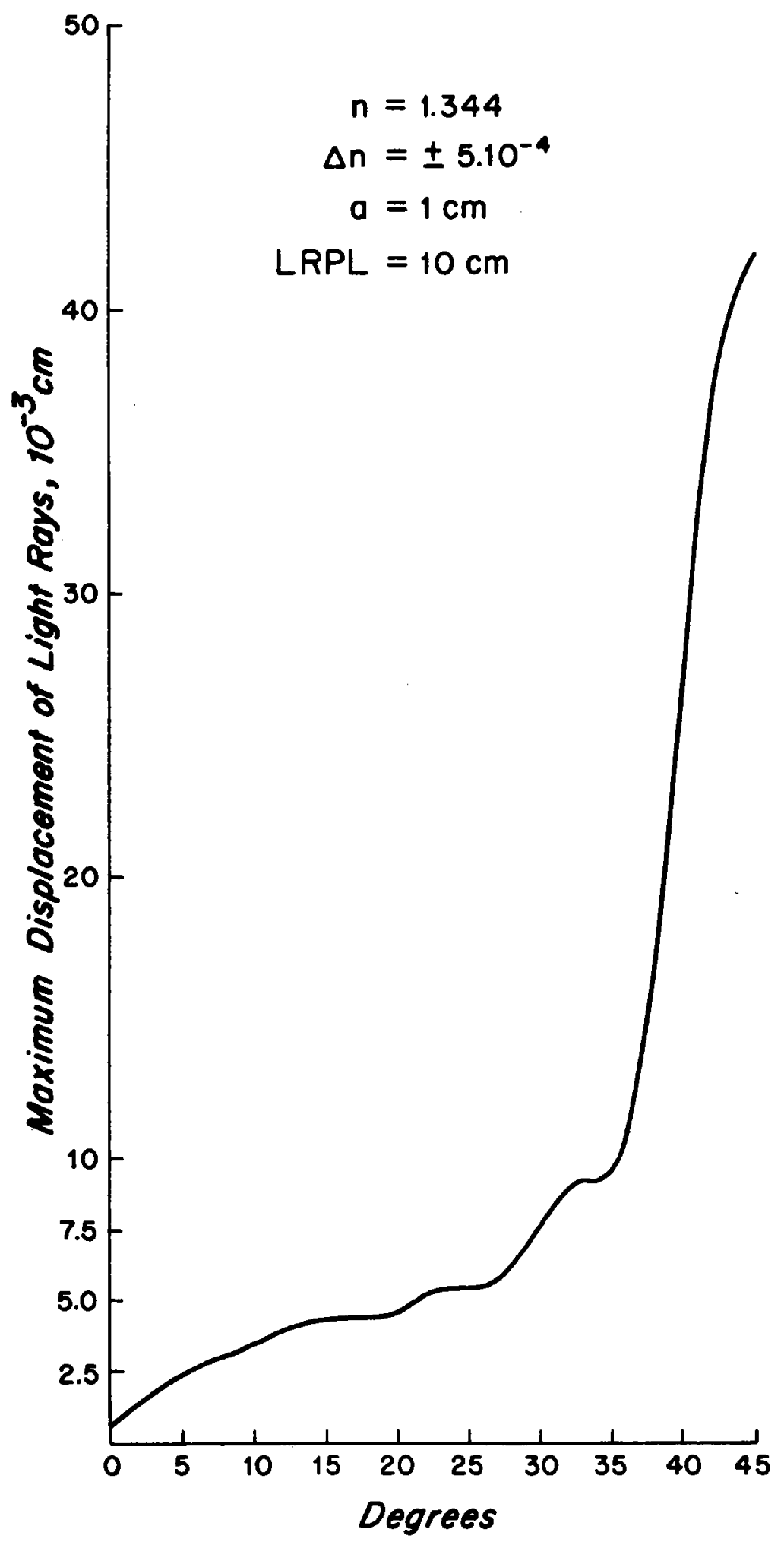

Figure 16. Maximum displacement of light rays for initial angles from $0^{0}$ to $45^{\circ}$. 


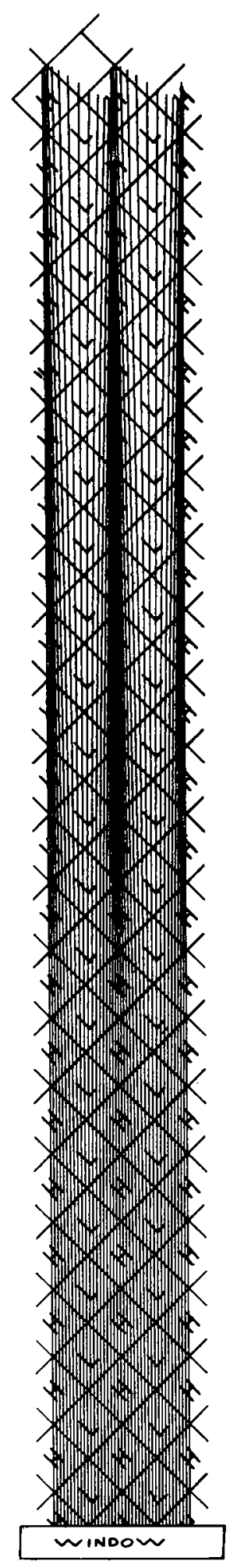

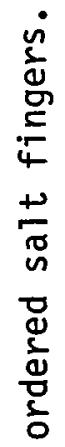

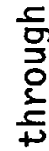

돔

4

을

ర্]

वे

I

章 


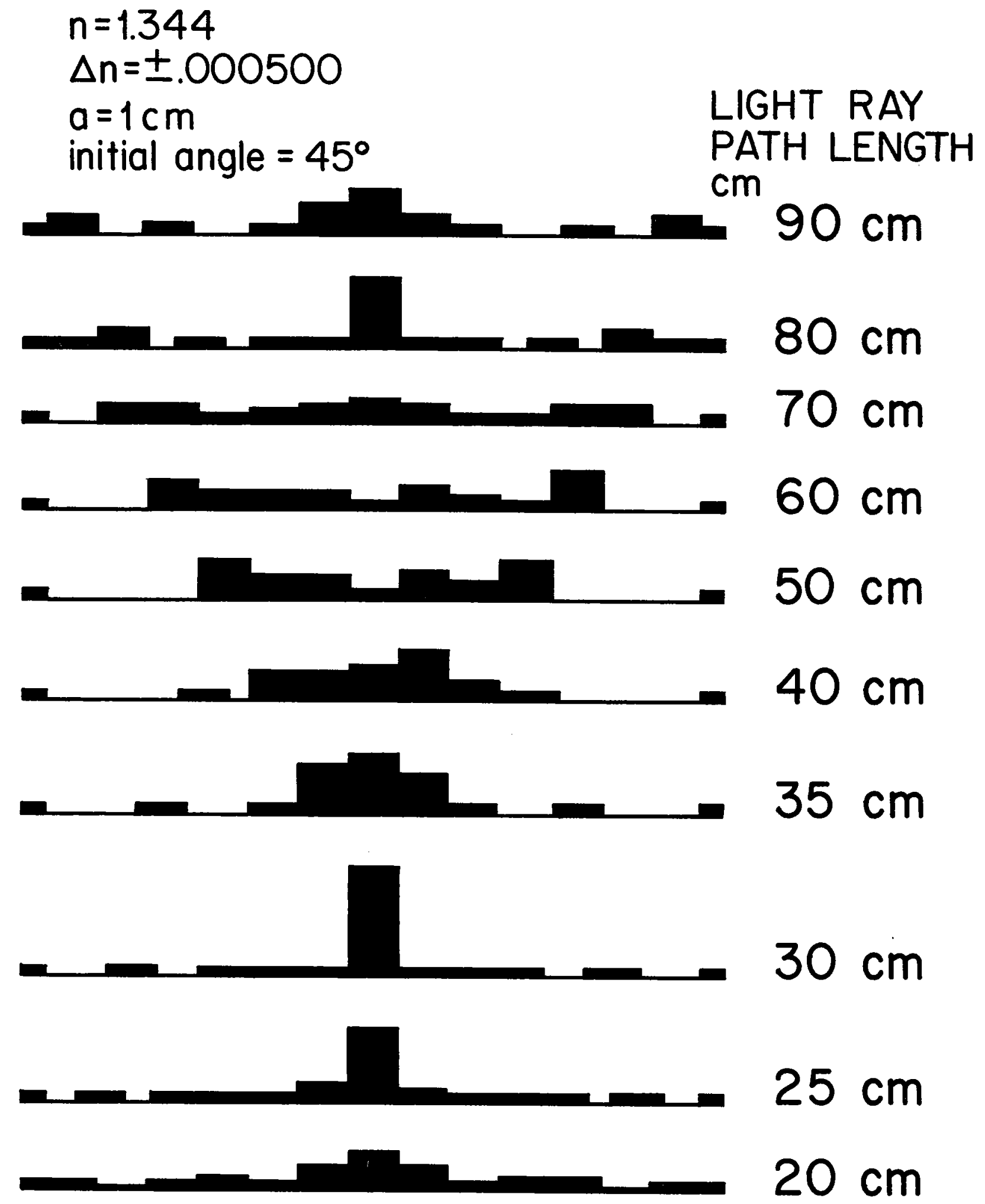

Figure 18. Intensity fluctuation versus light ray path length. 


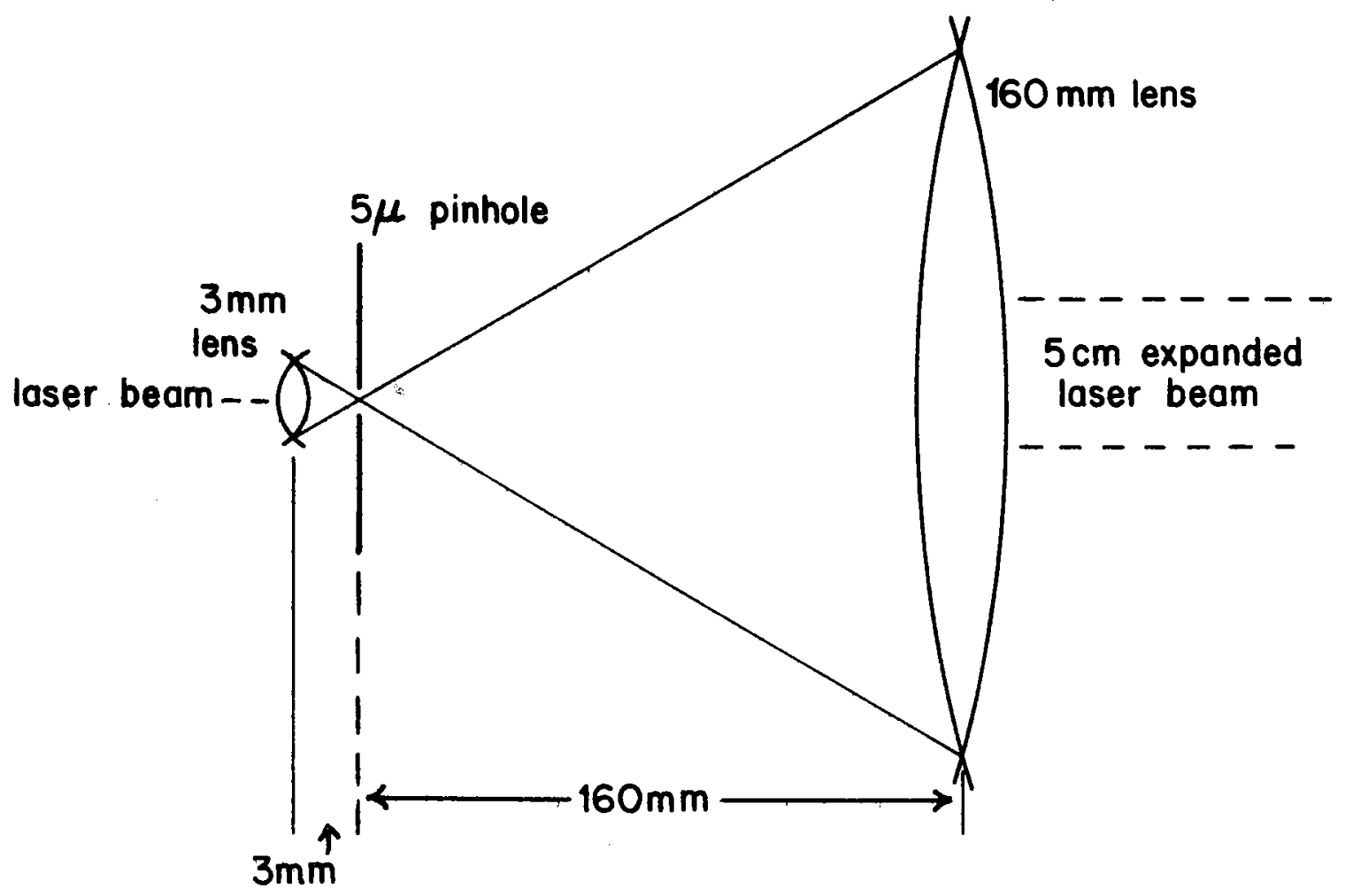

Figure 19. Laser beam expander. 


$$
0=\delta / 2 \alpha
$$

where 0 is the object distance,

$\delta$ is the cell size, and

$\alpha$ is the angle of deviation

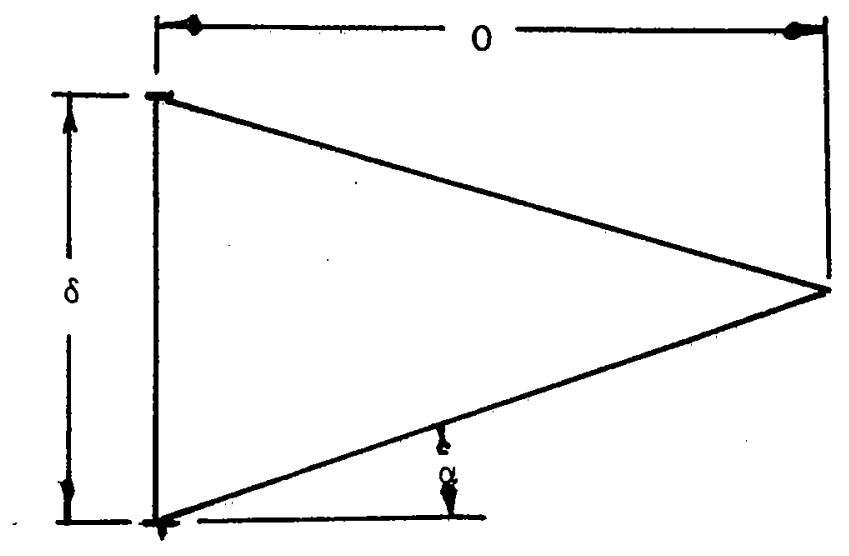

Figure 20. Object distance of a shadowgraph.

gives us an object distance of 200 meters which means we would need a shadowgraph optical path length on the same order of the object distance to obtain a sharp shadowgraph. We can shorten this optical path with a telescopemicroscope lens system here termed "shadowgraph shortener."

If we use thin lens theory for the $160 \mathrm{~mm}$ focal length telescope objective, the image distance necessary to obtain a sharp shadowgraph is:

$$
I=\frac{0 f}{0-f}
$$

where $I$ is the image distance from the lens and

$f$ is the focal length of the lens. Using the above example gives an image distance of 160.13 millimeters which is a more manageable length to use in an ocean instrument package. Again, using thin lens theory we can determine the size of the finger image, 


$$
M=\frac{I}{0}
$$

where $M$ is the magnification factor, and

$$
\delta_{1}=\delta \cdot M
$$

where $\delta_{1}$ is the finger image size.

Therefore, the image size is now only eight microns wide. To increase the image size, we must add one or two short focal length lenses to expand this small image (see Figure 21). Table 1 shows several calculations of different cell size and angles of deviation. From this table we note that we have reduced the simple shadowgraph path length range of one to four hundred meters down to around four hundred millimeters.

The final image falls on the ground glass screen and is photographed from behind the screen. 

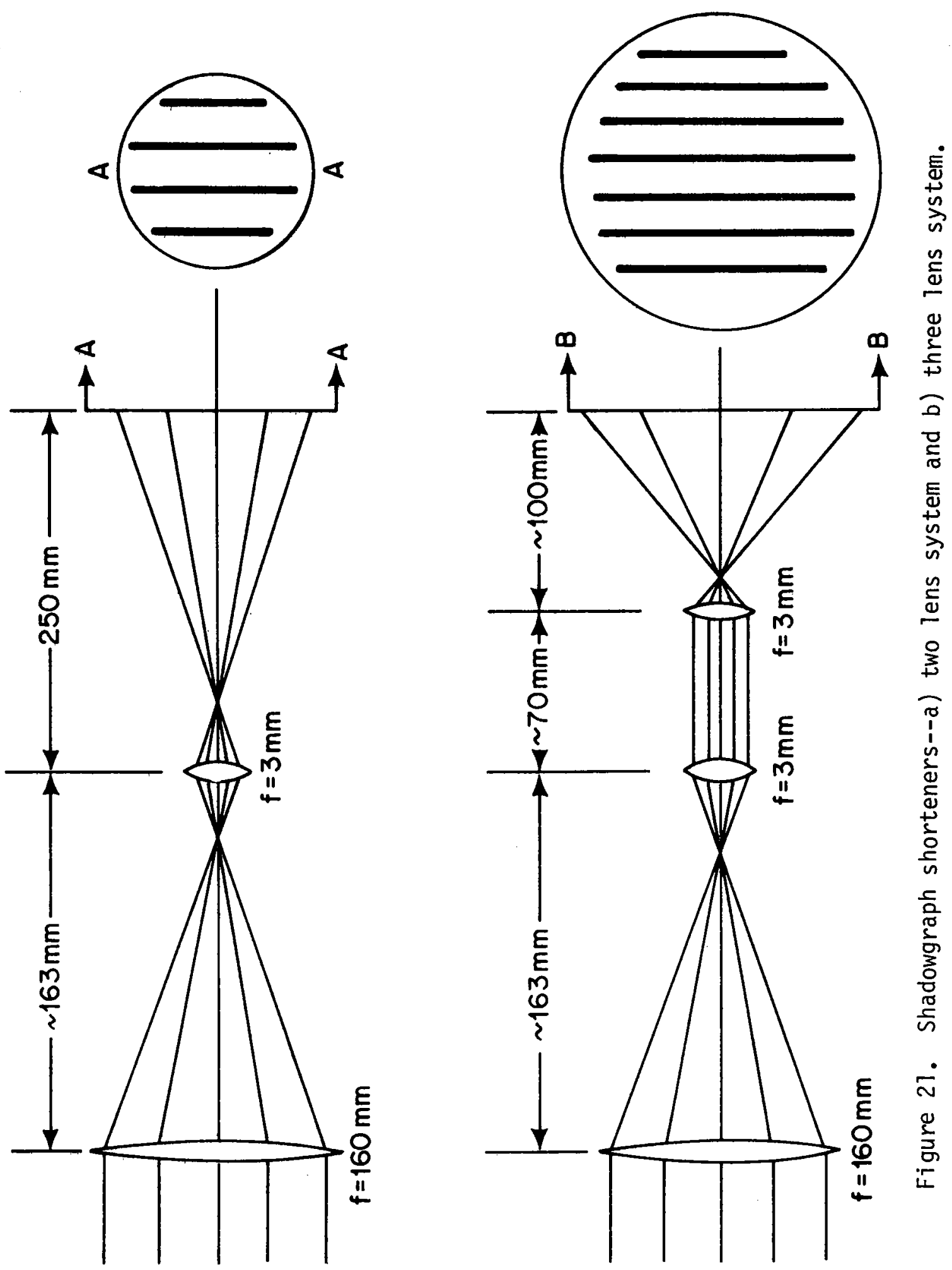


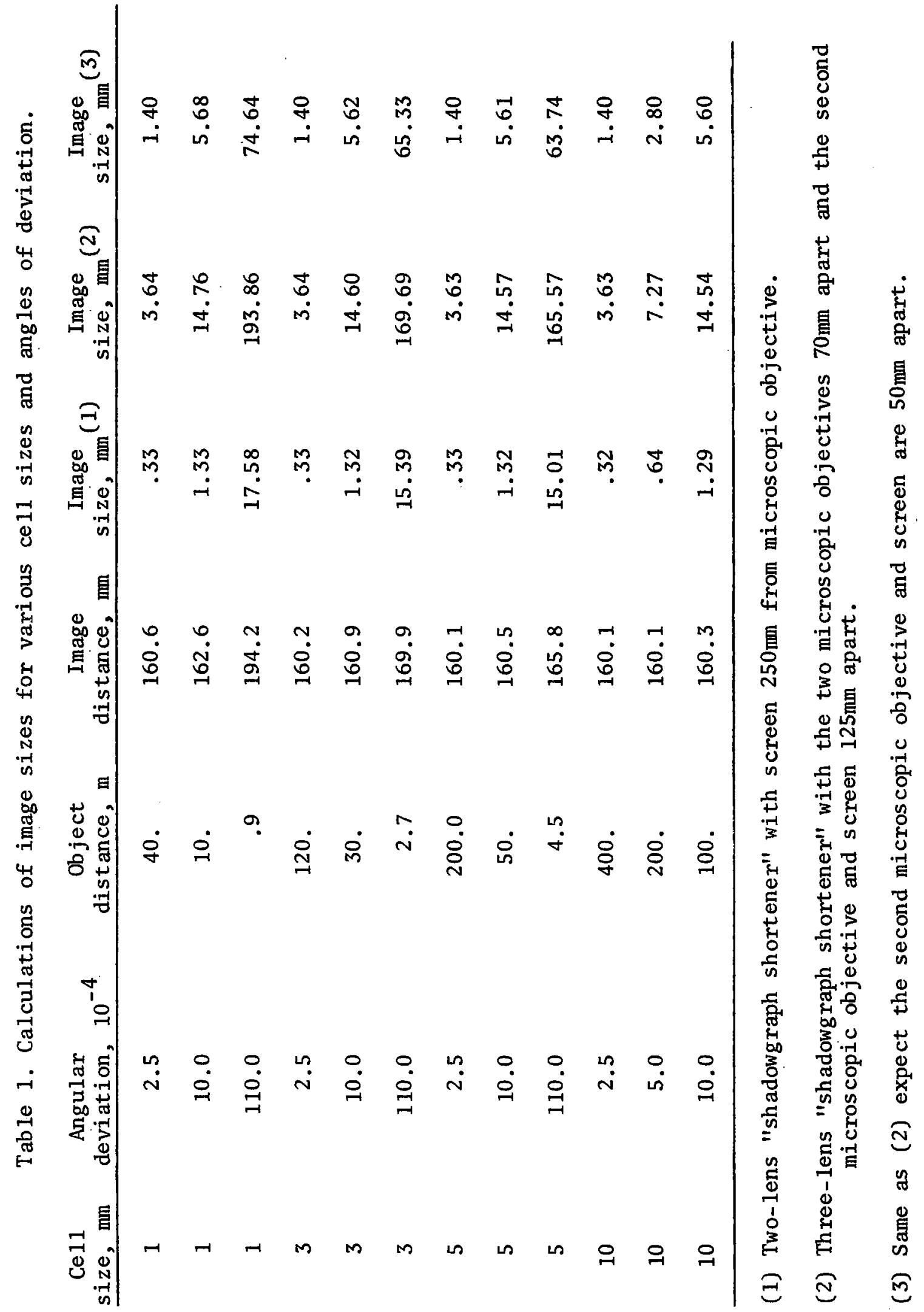




\section{EXPERIMENTAL SET-UP AND PROCEDURE}

For s source of parallel light rays, a low-powered helium-neon laser which produced a 5 millimeter-wide light beam was used. A laser was used because it is bright; that is, it has a lot of energy per unit area and per unit solid angle. (Bright sources can be collimated with little loss of energy). The laser beam was expanded using a collimator which consisted of the elements shown in Figure 19. A series of mirrors angled $45^{\circ}$ to the light beam axis reflected the light down one periscope, through a large tank of salt water, up a second periscope, and through the "shadowgraph shortener" onto a ground glass screen to be photographed from behind by a $16 \mathrm{~mm}$ motion picture camera (see Figure 22). The "shadowgraph shortener" consisted of the lens combinations as shown in Figure 21 . The ground glass screen was used to produce a real image of the laser beam to allow the experimentor to see when some indication of salt fingering was occurring so that the motion picture camera would be operated at the best time. A $16 \mathrm{~mm}$ motion picture camera was used since it can take a very large number of pictures on one roll of film (4000 pictures per hundred feet of $16 \mathrm{~mm}$ film) when it is used in an ocean instrument.

A large tank was used in conducting the experiments to reduce the ordering and orientation of salt fingers caused by the wall. To generate the salt fingering, the water surface was heated by two 250 watt heat 1 amps which were positioned from 50 centimeters to 150 centimeters above the water surface. Evaporation at the surface coupled with stable stratification produced by the heating gave profiles of temperature and salinity which decreased with depth. After the above process had been operating for a while, salt fingers were produced. 


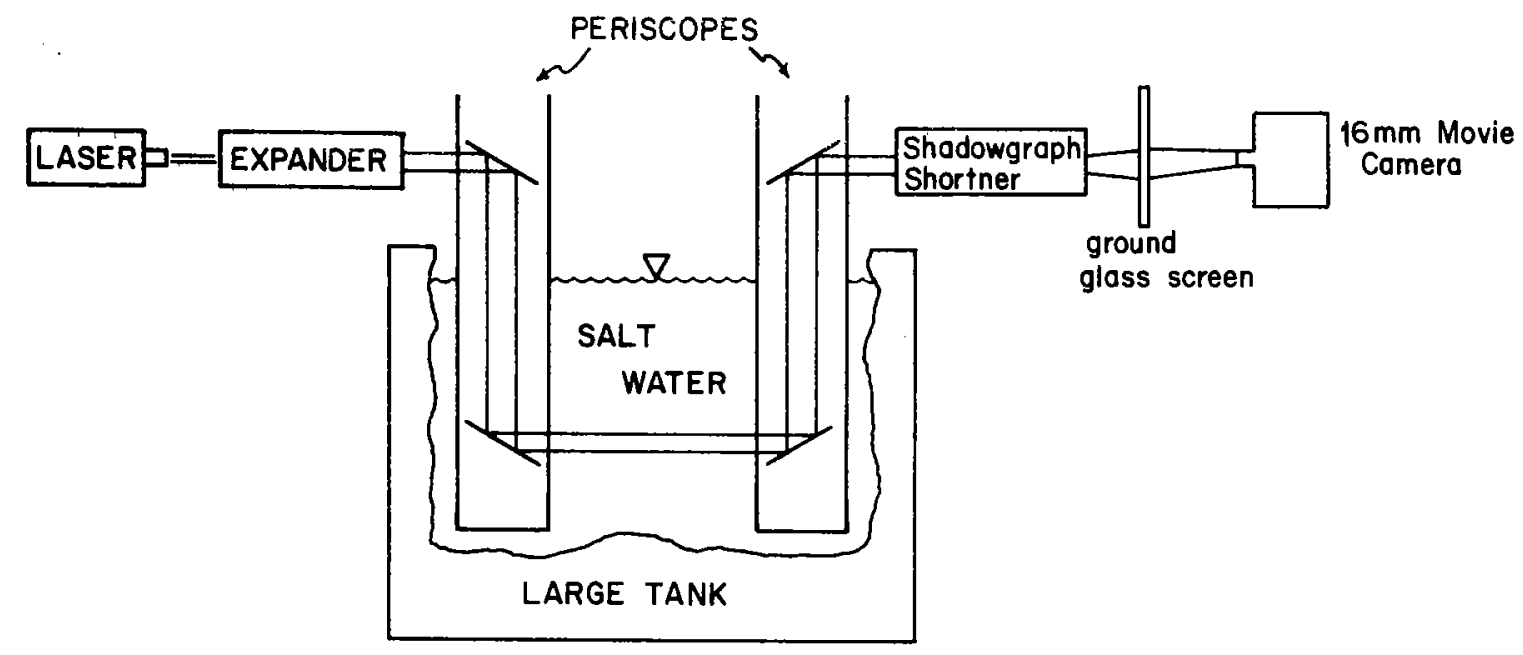

Figure 22. Schematic of experimental setup. 
To measure the temperature, a glass bead thermistor which was calibrated to $\pm 0.005^{\circ} \mathrm{C}$ was used with a digital ohmmeter to read the thermistor's resistance. To get the salinity, water samples were drawn from various depths with a glass tube. The samples were measured later with a laboratory salinometer to \pm 0.005 parts per thous and.

Several experiments were conducted, but only two of them will be discussed. In the first experiment the following procedure was used:

1. A batch of salt water was made up from filtered tap water and Kosher salt with a specific gravity of about 1.027 .

2. A two lens "shadowgraph shortener" was used as shown in Figure 21a.

3. The heat lamps were set about one half meter above the water surface, turned on, and left on continuously throughout the experiment except when the camera was operating.

4. After the heat lamps had been on for an hour the camera was operated for about half a minute, a temperature profile was obtained by recording resistance in intervals of 2.5 centimeters above and below the beam path, and three water samples were taken at the beam path level and five centimeters above and below the path to be measured later.

5. Step 4 was repeated two more times at intervals of an hour.

6. After the heat lamps had been on for four hours, the salt water was stirred to see if the vertical bands of light observed on the ground glass screen were destroyed.

The second experiment that will be discussed was conducted as the first experiment was except for the following:

1. The "shadowgraph shortener" consisted of the three-lens combination as shown in Figure $21 \mathrm{~b}$. 
2. The heat lamps were set one and a half meters above the water surface.

3. The first camera run was conducted twenty one hours after the heat lamps were turned on.

4. The temperature measurements and salinity samples were taken at intervals of six centimeters.

5. Two more runs were conducted an hour apart.

6. The heat lamps were turned off after 23 hours of operation, and four more runs were conducted at intervals of an hour to see if salt finger indications disappeared. 


\section{RESULTS AND DISCUSSION}

After the heat lamps were on for about one hour in the first experiment, a shadowgraph was obtained which is shown in Figure 23 a along with its temperature and salinity profile. From the salinity profile, we get a salinity gradient of $0,4 \%$ over 5 centimeters, which is about four hundred times greater than the total gradient over 50 meters measured in the ocean.

From the vertical bands in the picture (Figure 23a), it is the author's conclusion that salt fingers existed in the tank of sea water at the time of the photograph. The picture obtained is similar to the shadowgraph of sugar-salt fingers shown in Figure 1. From the picture it appears that the salt finger cell size is about 5 to 6 millimeters. The rings in the picture are believed to be Newton's rings due to reflections between the lenses.

The shadowgraphs obtained in the next two hourly runs of the above experiment were similar to the first one except that the bands were not as straight and distinct. After conducting the experiment for four hours, the water was stirred to see if the band pattern was destroyed, thus indicating the absence of salt fingers (see Figure $23 \mathrm{~b}$ for the recorded sh adowg raph).

In the second experiment where two microscope objectives were used in the "shadowgraph shortener," the first indication of salt fingering was obtained after the heat lamps had been on for twenty-two hours (see Figure 24a). The salinity gradient at this time was only $0.02 \%$ over 6 centimeters which is only one order of magnitude larger than the 50 meter total gradient found in the ocean. The shadowgraph is not very distinctive 


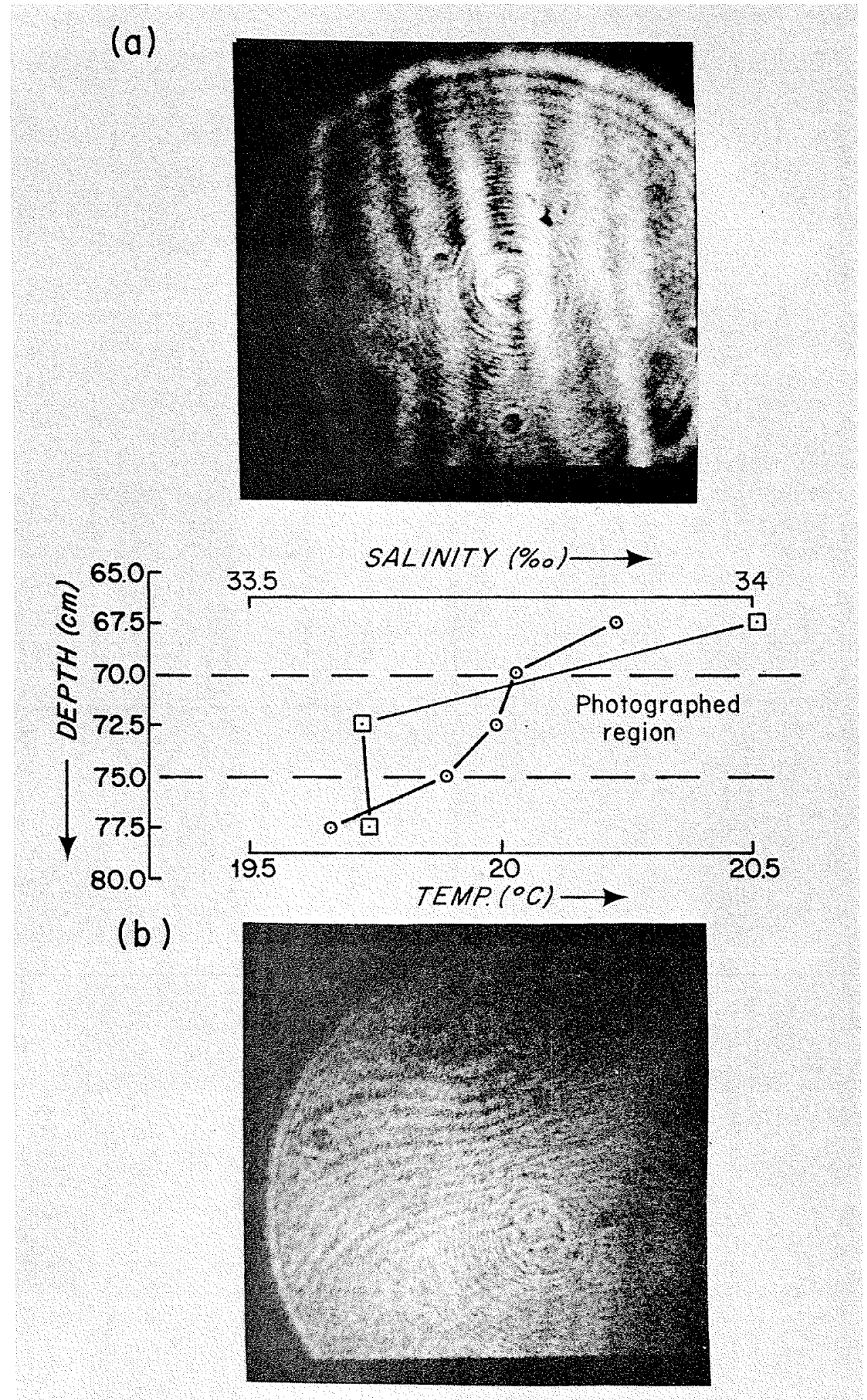

Figure 23. Shadowgraph results--a) after one hour with its corresponding temperature and salinity profiles, b) after four hours and mixing. 


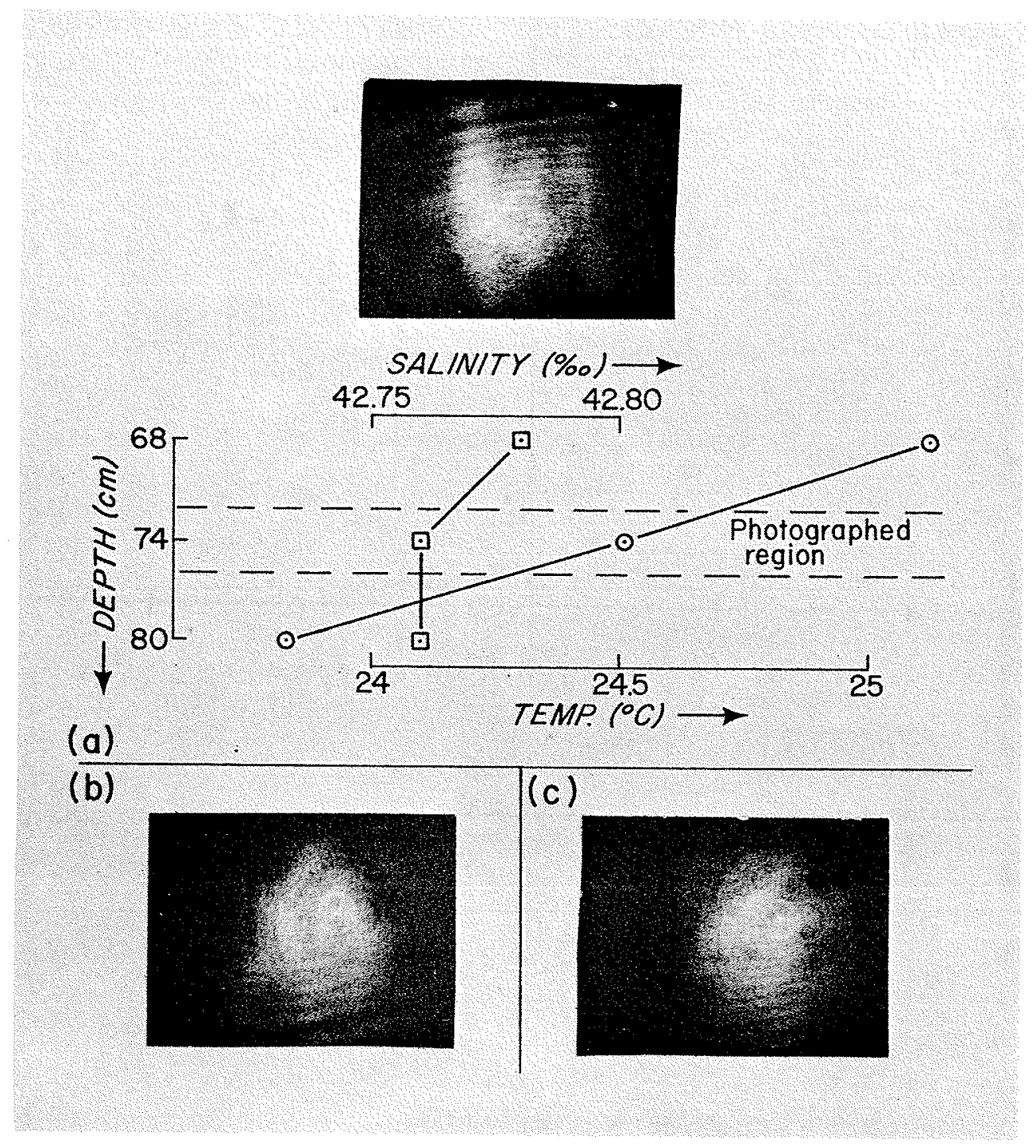

Figure 24. Shadowgraph results--a) after twenty-two hours with its corresponding temperature and salinity profiles, b) after twenty-one hours, c) after twenty-five hours. 
in comparison with the first experiment's results, but there appears to be three bright bands with two of the bands blending together near the center. One problem with the two microscope objective "shadowgraph shortener" was that the light beam exited the second microscope objective with a wideangled cone which caused a "hot spot" in the center of the screen. (This condition was later eliminated with a Fresnel field lens over the ground glass.) When the above shadowg raph is compared with two other shadowgraphs of which one was obtained one hour earlier (Figure 24b) and the other (Figure 24c) three hours later (after the heat lamps were turned off for two hours), one sees that the previously mentioned shadowgraph (Figure 24a) is an indication of salt fingering. The shadowgraph (Figure 24c) that was photographed after the heat lamps had been turned off for two hours seems to indicate that salt fingering had died down since the driving process is changed.

The biggest problem with the above optical set-up is the guess work that is necessary in deciding on the spacing of the "shadowgraph shortener" lenses and the ground glass screen in order to produce a sharp shadowgraph of salt fingers of a specific strength. Fortunately there is a depth of field similar to that obtained with a camera lens that will allow one to see salt fingers weaker or stronger than a specific strength even though the image will be less sharp as one moves away from the optimum strength of salt fingers. It should be possible to reduce the guess work with a lot of field work looking for salt fingers.

One advantage of the optical method used in the shadowgraph experiments is that a 12 volt battery can operate both the laser and the camera which would free a salt finger detector from having to be tethered to a surface 
vesse1. The movie camera used in the above experiments can hold 400 feet of $16 \mathrm{~mm}$ film. If a salt finger detector was attached to a slow moving free fall instrument with a fall rate of five centimeters per second and the camera was operated at 60 frames per minute, 800 meters of the vertical ocean structure could be recorded on one dive.

It is desirable to know the salinity and temperature gradients when there is any indication of salt fingering on the film taken by an optical salt finger detector. By knowing the gradients, it would help in the guess work of setting the spacing of the "shadowgraph shortener" lenses and the ground glass screen when other ocean areas are investigated. Also, the gradients data may help in understanding the salt fingering process.

From the results of the experimental and theoretical computer work, it was decided to design and build an optical salt finger detector (OSFD) using the same basic set-up as used in the laboratory. The designing procedure and reasoning is explained in Appendix B.

The OSFD is housed in a $41 / 2$ foot, 12 inch outer diameter aluminum tube with a hemispherical end cap on one end and a flat end plate on the other. The flat end plate has two port holes covered by a single glass window.

The optical equipment is arranged in the following manner:

1. The collimator and "shadowgraph shortener" are aligned paralle1 to each other side by side just behind the two port holes in the flat plate.

2. The laser is behind the collimator and the ground glass screen is behind the "shadowgraph shortener." 
3. The $16 \mathrm{~mm}$ movie camera, which fills the tube, is behind the laser and the ground glass screen.

4. A 12 volt Ge1 cell which powers the laser and the movie camera is last in line, just inside the hemispherical end cap. The camera and battery can be removed from the pressure housing without disturbing the alignment of the other optical components.

The laser beam is spatially filtered and expanded in the collimator. Then the beam goes through a view port to be reflected back through the second view port by two front surface mirrors set $90^{\circ}$ to each other to form a corner reflector one meter from the view ports. The booms that hold the mirrors are on the sides of the light paths so that they do not stir the observed water as the OSFD sinks. The reflected beam then goes through the second view port and the "shadowgraph shortener" to fall on the ground glass screen where it is photographed by the camera. The alignment of the microscope objective in the "shadowgraph shortener" is achieved with two orthogonal micrometer screws. Since the micrometers are too far down the tube to reach, drums were rigged on them so they can be adjusted by pulling on strings.

When the OSFD is used in the ocean, the Autoprobe will lower and raise it along with a conductivity, temperature, and depth (CTD) probe. The Autoprobe is a free-floating mid-water observational platform, built by Kenneth Burt of Woods Hole Oceanographic Institution, that is capable of changing its displacement under programmed electronic control or by acoustic command. To synchronize the film data with the CTD profile, sixteen small light emitting diodes were arranged around the ground glass screen to be photographed along with the salt finger data. These lights produced a binary code which is controlled by the clocking mechanism in the CTD probe. 
REFERENCES

Albro, Carl S. and T. Gray Curtis, Jr., 1971, "Detection of Salt Fingers by Eclipsed Schlieren Technique," in Report of the Oceanographic Engineering Summer Report by Daubin, Scott C., Woods Hole Oceanographic Institution, Reference No. 71-5, p. 46-66 (unpub1ished manuscript).

Cooper, John W. and Henry Stommel, 1968, "Regularly Spaced Steps in the Main Thermocline near Bermuda," Journal of Geophysical Research, Vol. 73, No. 18, p. 5849-5854.

Eriksen, Charles Curtis, V, 1971, "Heat-Salt Fingers: An Experimental Study Using Optical Detection," (unpublished manuscript).

Fischer, Hugo B., 1971, "The Dilution of an Undersea Sewage Cloud by Salt Fingers," Water Research, Vol. 55, p. 909-915.

Fulgister, F.C., 1960, "At lantic Ocean Atlas of Temperature and Salinity Profiles and Data from the International Geophysical Year of 19571958," published by Woods Hole Oceanographic Institution.

Howe, M.R, and R.I. Tait, 1970, "Further Observations of Thermohaline Stratification in the Deep Ocean," Deep-Sea Research, Vo1. 17, p. 963-972.

Kim, M.G., R.B. Lambert, and S.V. Letcher, 1971, "Investigation of Doub leDiffusive Convection Using an Ultrasonic Pulse-Echo Technique," Journal of the Acoustical Society of America, Vol. 50, No. 5 (Part 2), p. 1389-1392.

Stern, Melvin E., 1969, "Collective Instability of Salt Fingers," Journal of Fluid Mechanics, Vo1. 35, Part 2, p. 209-218.

1970, "Optical Measurement of Salt Fingers," Te11us, XXII, p. $76-81$.

, 1960, "The 'Salt-Fountain' and The rmohaline Convection," Te1lus, XII, 2 p. 172-175.

, and J. Stewart Tumer, 1969, "Salt Fingers and Convecting Layers," Deep-Sea Research, Vo1. 16, p. 497-511.

Metcalf, William G. and Marvel C. Stalcup, 1969, "Current Meter and Hydrographic Station Data from CRAWFORD Cruise \#165, In the Tropical At lantic Ocean, February-April 1968," Woods Hole Oceanographic Institution Reference No. 69-72, (unpublished manuscript).

Shirtcliffe, T.G.L, and J.S. Turner, 1970, "Observation of the Ce11 Structure of Salt Fingers," Journal of Fluid Mechanics, Vol. 41, Part 4, p. 707-719. 
Stomme1, H., Arons, A.B., and Blanchard, D., 1956, "An Oceanographical Curiosity, the Perpetual Salt Foumtain," Deep-Sea Research, Vol. 3, p. $152-153$.

Turner, J. Stewart, 1967, "Sa1t Fingers across a Density Interface," Deep-Sea Research, Vo1. 14, p. 599-611. 
APPENDIX A - COMPUTER FLOW CHART OF RAY TRACING PROGRAM

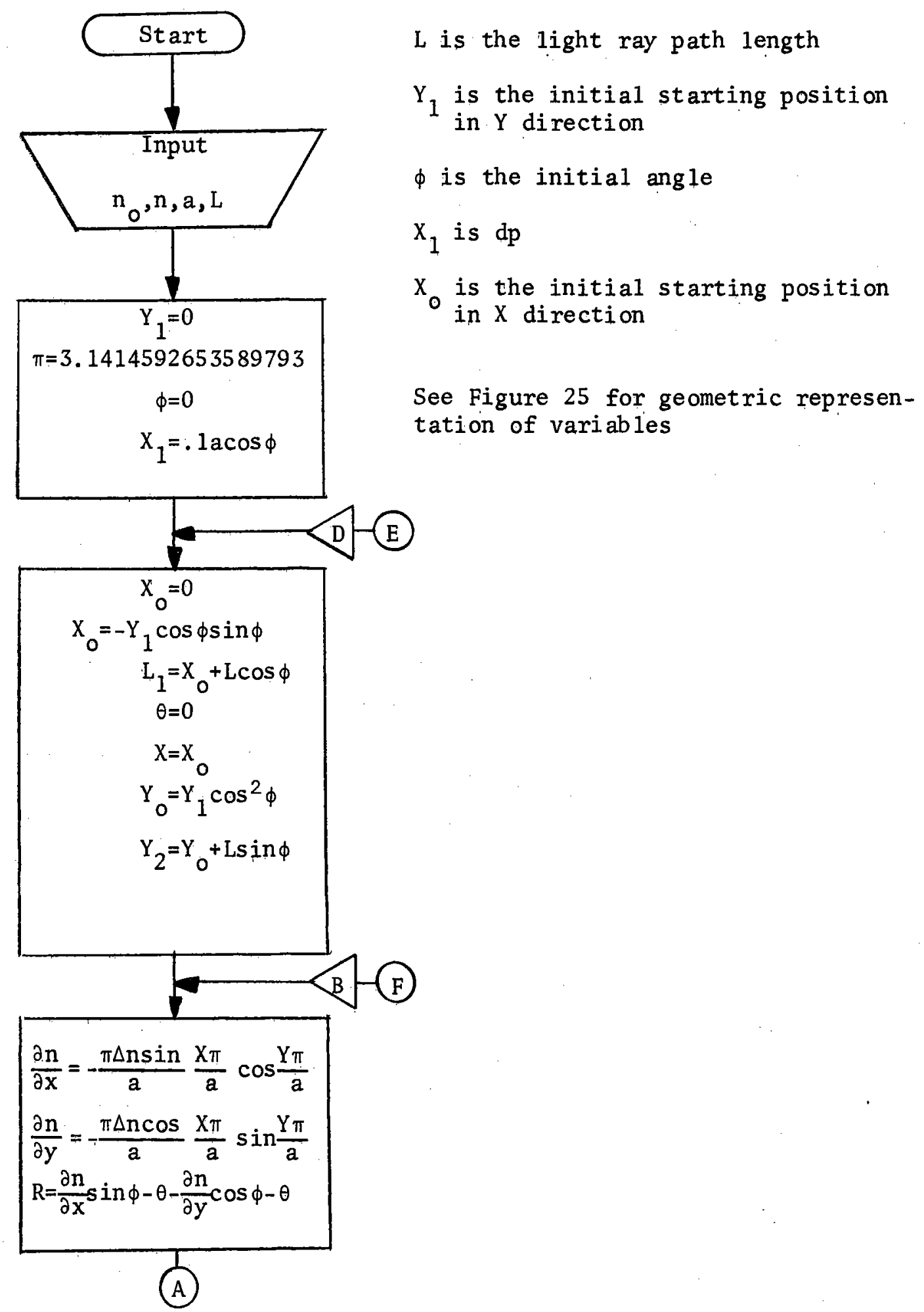




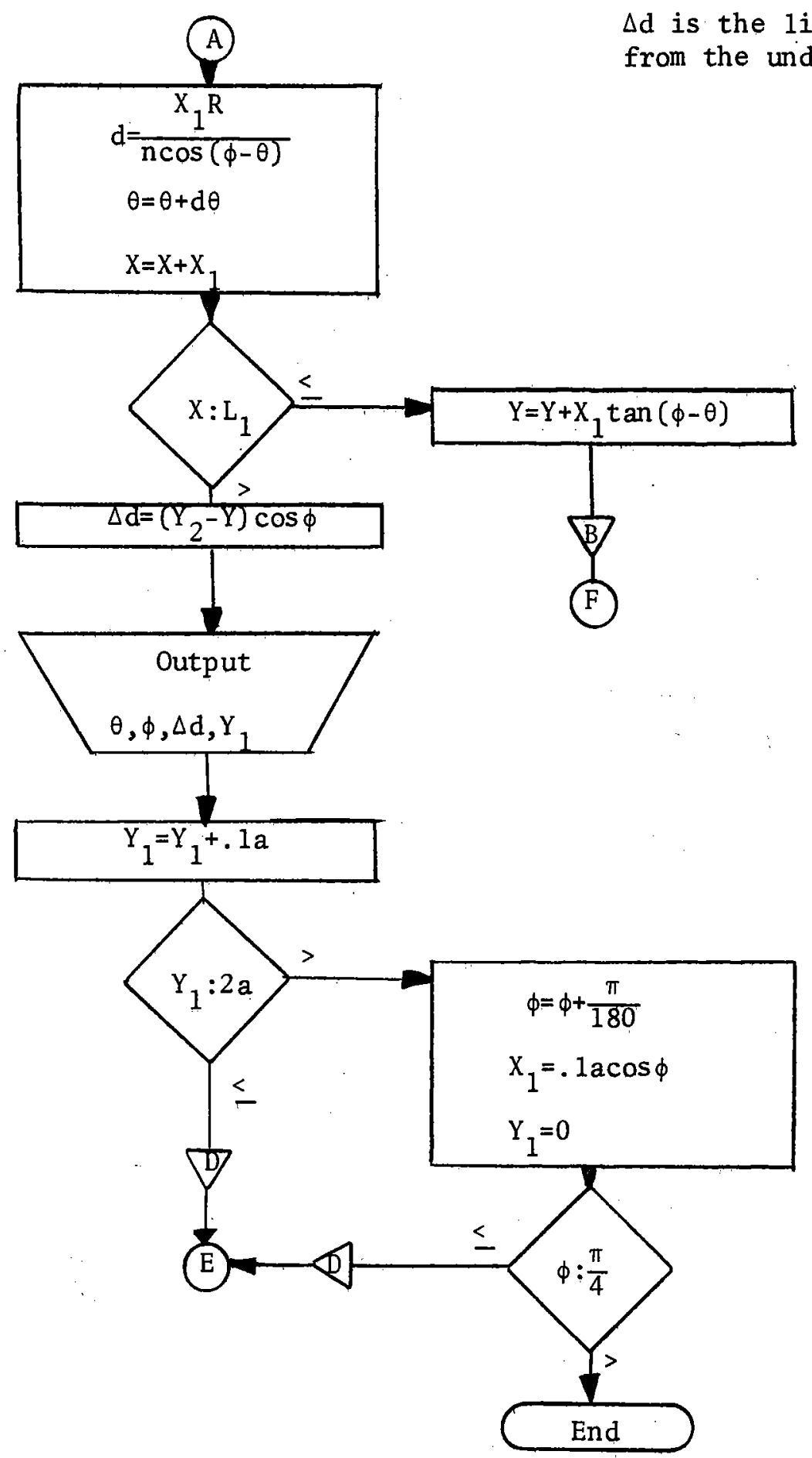




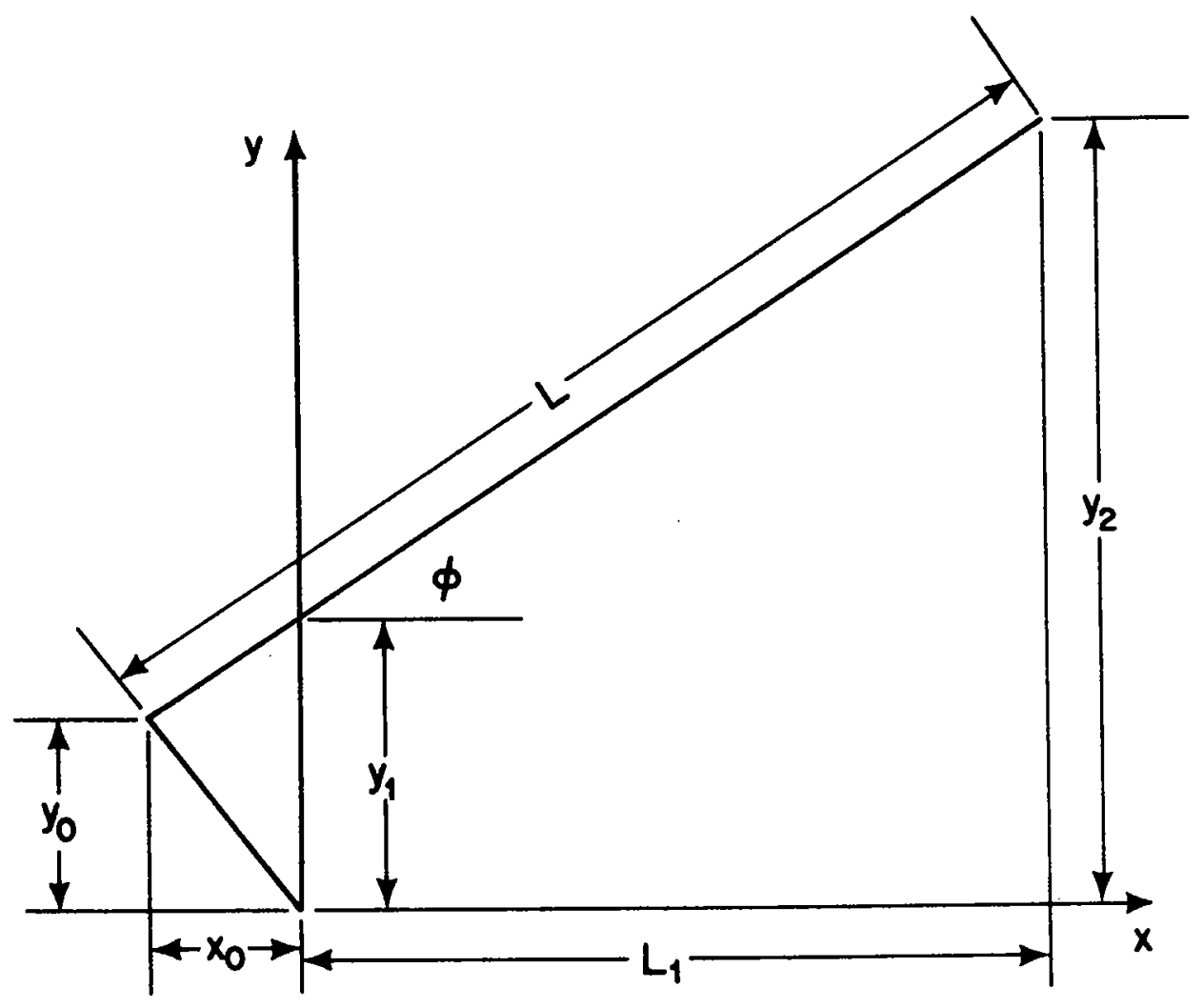

Figure 25. Geometric representations of some of the terms in the computer program. 
APPENDIX B - OPTICAL SALT FINGER DETECTOR DESIGN

From the results of the experiments and theoretical work on the computer, it was decided to design and build an Optical Salt Finger Detector, OSFD, using the same principle as the lab set-up. It is desirable that the OSFD meet the following design restraints:

1. It needs a pressure housing big enough to contain the $16 \mathrm{~mm}$ movie camera which is the largest optical component.

2. Operational depth is set at 2000 meters which is the lower depth of layering that has been found at the Mediterranean outflow.

3. It:is to be neutrally buoyant so that the Autoprobe can lower and raise the OSFD in the ocean.

4. It must have an undisturbed region of salt fingering between the light source and the recording element.

5. It needs view ports to allow the laser beam to exit and re-enter the pressure housing.

6. A power supply is required to operate the laser and the $16 \mathrm{~mm}$ movie driving mechanism.

7. It is to have a timing mechanism to synchronize the film data with a CTD probe (A CTD probe will be lowered with the OSFD by the Autoprobe).

To meet the first three restraints, an aluminum 6061-T6 tubing was selected having an internal diameter of $101 / 2$ inches, an external diameter of 12 inches and cylindrical length of $41 / 2$ feet. For end caps to seal off the ends of the tubing, it would have been desirable to have hemispherical end caps since they are almost neutrally buoyant, but the need for a 
pair of view ports indicated that one of the end caps should be flat. After deciding on a flat end plate for one end and a hemispherical end cap for the other, the method of attaching them to the cylinder was considered. Bolting was rejected for reasons of corrosion and Marmon V-band clamps were rejected for wall reduction and corrosion reasons. Internal clamping was selected as loss in internal diameter was tolerable at the window end. A ring drilled for bolts was shrunk into the tube about one inch from one end of the cylinder. Then the flat end cap was held to the cylinder by internally bolting the cap to the shrink ring. The hemispherical end was held to the cylinder by a pair of tie rods anchored in the flat end plate which held a tapped bar into which the hemispherical end cap was bolted. The bolt was later covered with a small aluminum cap (see Figure 26). The last method was chosen since there are no dissimilar metals exposed to sea water so corrosion is kept to a minimum. Also, the cylinder wall is not weakened with this method as compared to the other methods.

Figure 27 shows three configurations that could be used to provide an undisturbed region of salt fingering between the light source and the recording element. The configuration "27c" was chosen for the design of the OSFD since the design has several advantages over the other two configurations :

1. Only one pressure housing is necessary which in turn reduces the number of windows and end caps.

2. The collimator and the "shadowgraph shortener" can be aligned to each other by having them parallel to each other with the two mirrors set $90^{\circ}$ to each other to reflect the light beam from the collimator into the receiver. 
$-49-$

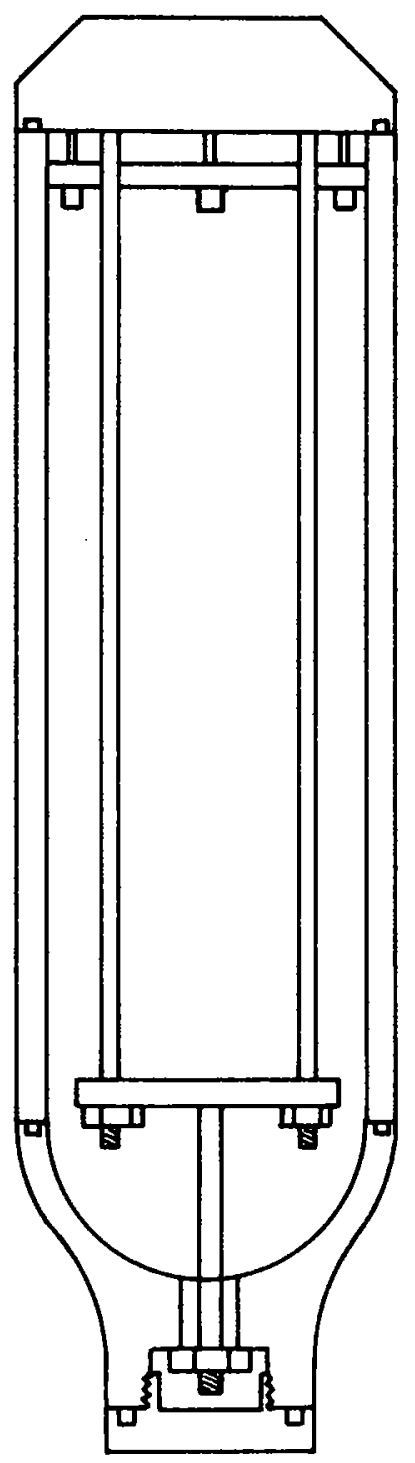

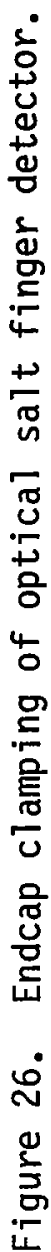


A

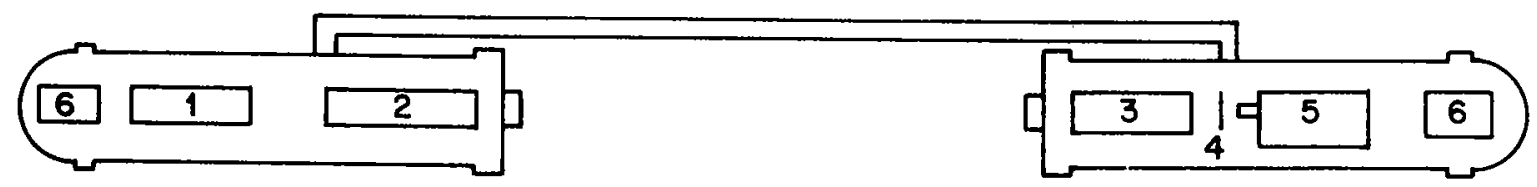

B

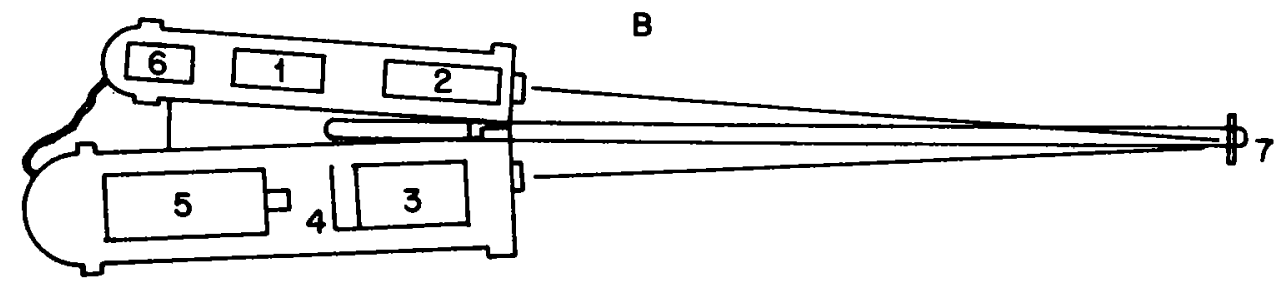

C

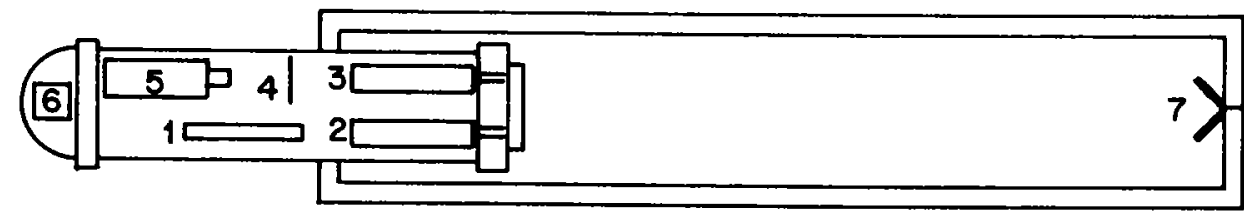

1-LASER , 2-EXPANDER , 3-"SHADOWGRAPH SHORTNER" , 4- GROUND GLASS SCREEN, 5-CAMERA , 6-BATTERY , 7-MIRRORS

Figure 27. Three possible configurations of the optical salt finger detector. 
3. The total volume of the pressure housing is less since the light source overlaps the receiver, thus also reducing the overall weight of the OSFD.

A 12 volt Gel1 cell was selected as the energy source to operate the laser and the $16 \mathrm{~mm}$ movie camera driving mechanism. About eight hours of operation is possible before recharging is necessary.

To synchronize the film data with the CTD data, sixteen small red LED lights were arranged around the ground glass screen to be photographed along with the salt finger data. These lights produce a binary code which is controlled by the clocking mechanism in the CTD probe.

For the alignment requirement, it was decided to hold the laser, collimator, "shadowgraph shortener," and ground glass screen separate from the camera so that the alignment of the latter components remain fixed when the camera was removed from the presure housing to change the film. Since the instrument will be aligned in air, it was desired that the expanded laser beam exit perpendicular to the view port in order for the alignment to remain the same when the instrument is immersed in the water. A box channel design was selected to hold the four above mentioned components with the box channel being attached to the flat end plate to accomplish the view port alignment. The collimator and "shadowgraph shortener" are held parallel to each other by two parallel $\mathrm{V}$-grooves that were machined in an aluminum block which is in turn screwed to the box channel such that they are perpendicular to the flat end plate and on axis to the view. ports. The laser holder allows the laser to be moved vertically and sideways, pitched, and yawed to get it aligned with the collimator. The ground glass screen is aligned by a slotted rectangular groove in the 
bottom plate of the box channel which allows the screen to be moved toward or away from the "shadowgraph shortener" depending on the spacing of the lens to get $a$ one and a half inch image. Figure 28 shows the arrangement of the four components within the box channe 1 attached to the flat end plate.

The camera and battery are mounted on one holder to facilitate the removal of them from the inside of the cylinder. The holder has holes that the tie rods go through to serve as alignment guides for the camera. It was necessary to tilt the camera $45^{\circ}$ from the vertical to align the camera lens with the ground glass screen because of its shape and size. 


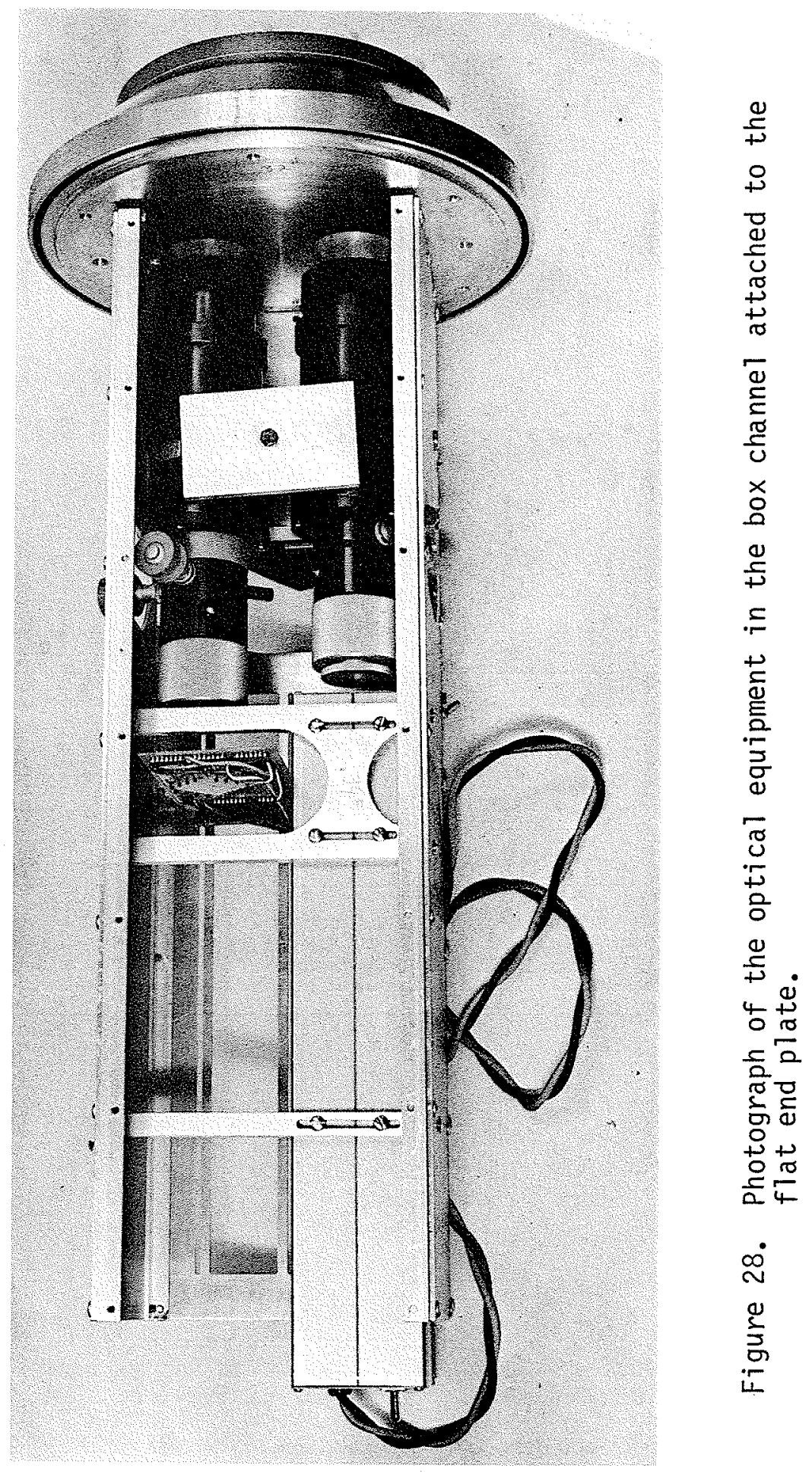


MANDATORY DISTRIBUTION LIST

FOR UNCLASSIFIED TECHNICAL REPORTS, REPRINTS, \& FINAL REPORTS

PUBLISHED BY OCEANOGRAPHIC CONTRACTORS

OF THE OCEAN SCIENCE \& TECHNOLOGY DIVISION

OF THE OFFICE OF NAVAL RESEARCH

(REVISED OCTOBER, 1972)

1 Director of Defense Research and Engineering

Office of the Secretary of Defense Washington, D. C. 20301

ATTN: Office, Assistant Director (Research)

12 Defense Documentation Center

Cameron Station

Alexandria, Virginia 22314

Office of Naval Research

Department of the Navy

Arlington, Virginia 22217

3 ATTN: Ocean Science \& Technology

Division, Code 480

1 ATTN: Naval Applications \& Analysis

Division, Code 460

1 ATTN: Earth Sciences Division, Code 410

1 Office of Naval Research

Branch Office

495 Summer Street

Bostoil, Massachusetts 02210

1 LCDR David Cacchione, (USN)

ONR Representative

Woods Hole Oceanographic Institution

Woods Hole, Massachusetts 02543

Director

Naval Research Laboratory

Washington, D. C. 20390

6 ATTN: Library, Code 2029 (ONRL)

6 ATTN: Library, Code 2000

\section{Commander}

Naval Oceanographic Office

Washington, D. C. 20390

1 ATTN: Code 1640 (Library)

1 ATTN: Code 70

1 Director

National Oceanographic Data Center

National Oceanic \& Atmospheric Administration

U.S.Dept. of Commerce

Rockville, Maryland 20852 


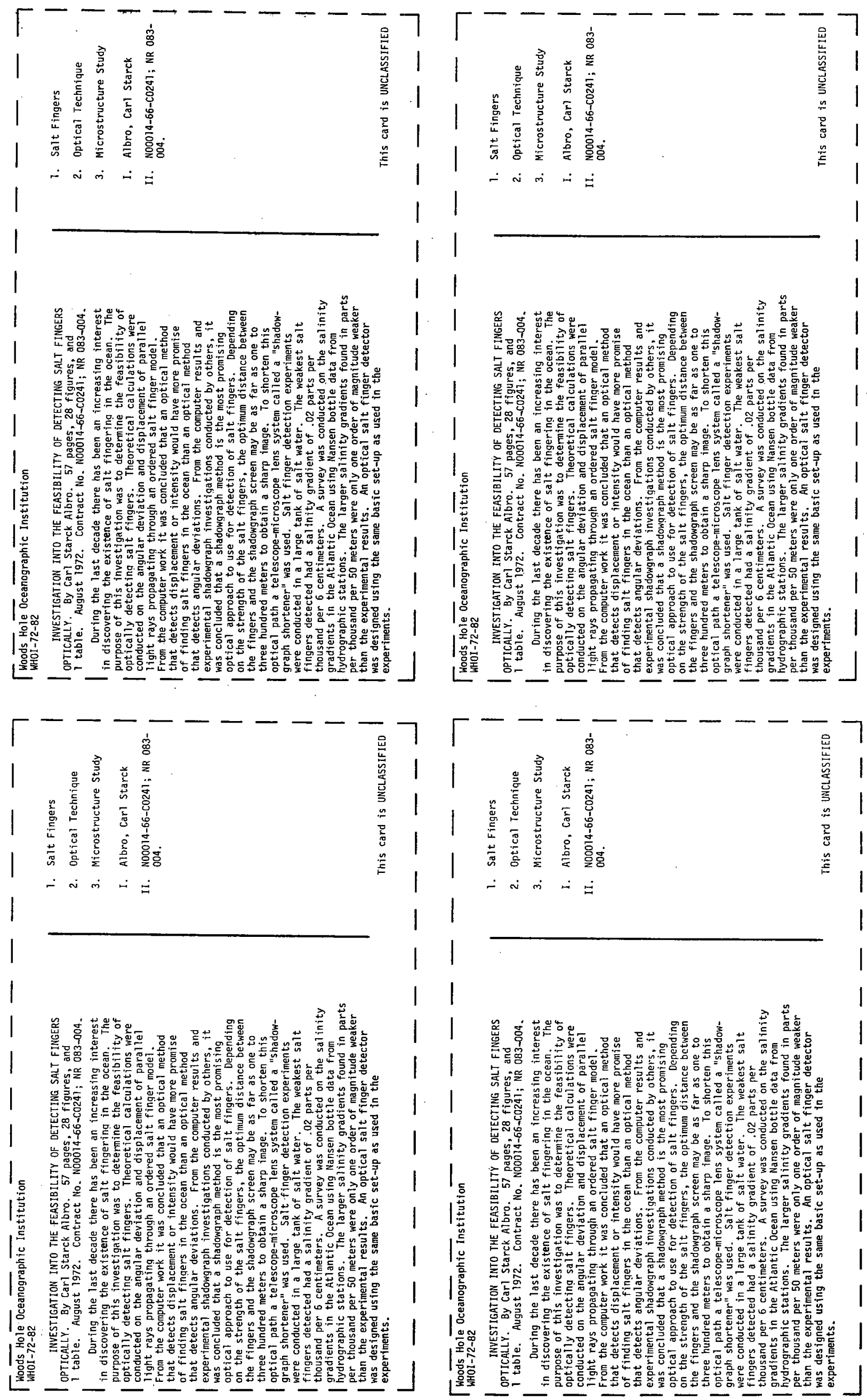


(Socurity ciasalllcation of title. body of abstrachignd indexing annalation must be entored when the overall report is classified) 1. ORIGINATIN G ACTIVITY (COMporgro author)

Woods Hole Oceanoaraphic Institution Woods Hole, Massachusetts 02543

2a. REPORT SECURITY CLASSIFICATION UNCLASSIFIED

2b. GROUP

3. REPORT TITLE

INVESTIGATION INTO THE FEASIBILITY OF DETECTING SALT FINGERS OPTICALLY

4. DESCRIPTIVE NO-ES (Typo of ropor! and inclusive dotes)

Technical Report

5. AUTHOR(S) (Last nạmo, first name, initial)

Carl Starck Albro

\begin{tabular}{|c|c|c|}
\hline $\begin{array}{l}\text { 6. REPORT DATE } \\
\text { AuguSt } 1972\end{array}$ & $\begin{array}{l}\text { 70. TOTAL NO. OF PA'GES } \\
57\end{array}$ & $\begin{array}{c}\text { 76. NO. OF REFS } \\
15\end{array}$ \\
\hline $\begin{array}{l}\text { B. CONTRACT OR GRANT No. } \\
\text { N00014-66-C0241; NR 083-004 } \\
\text { b. PROJEeT No. }\end{array}$ & \multicolumn{2}{|c|}{$\begin{array}{l}\text { 9A. ORIGINATOR'S REPORT NUMEER(S) } \\
\text { WHOI }-72-82\end{array}$} \\
\hline 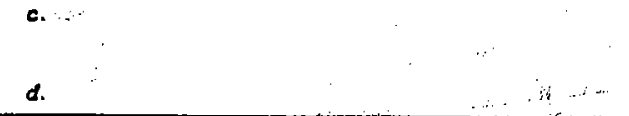 & \multicolumn{2}{|c|}{$\begin{array}{l}\text { 9b. OTHER REPORT NO(S) (A ny other numbers that may be assigned } \\
\text { ihis roport) }\end{array}$} \\
\hline
\end{tabular}

10. AYAILABILITY/LIMITATION NOTICES

Approved: for public release, distribution unlimited.

11. SUPPL EMEN TARY NOTÉS

12. SṔONSORING MILITAAY ACTIVITY

Office of Naval Research

Dcean Science \& Technology Division Arlington, Virqinia 22217

13. ABSTRACT

During the rast decade there has been an increasing interest in discovering the existence of salt fingering in the ocean. The purpose of this investigation was to determine the feasibility of optically detecting salt fingers. Theoretical calculations were conducted on the angular deviation and displacement of parallel light rays propagating through an ordered salt finger model. From the computer work it was concluded that an optical method that detects displacement or intensity would have more promise of finding salt fingers in the ocean than an optical method that detects angular deviations. From the computer results and experimental shadowgraph investigations conducted by others, it was concluded that a shadowgraph method is the most promising optical approach to use for detection of salt fingers. Depending on the strength of the salt fingers, the optimum distance between the fingers and the shadowgraph screen may be as far as one to three hundred meters to obtain a sharp image. To shorten this optical path a telescope-microscope lens system called a. "shadowgraph shortener" was used. Salt finger detection experiments were conducted in a large tank of salt water. The weakest salt fingers detected had a salinity gradient of .02 parts per thousand per 6 centimeters. A survey was conducted on the salinity gradients in the Atlantic Ocean using Nansen bottle data from hydrographic stations. The larger salinity gradients found in parts per thousand per 50 meters were only one order of magnitude weaker than the experimental results. An optical salt finger detector was designed using the same basic set-up as used in the experiments. 


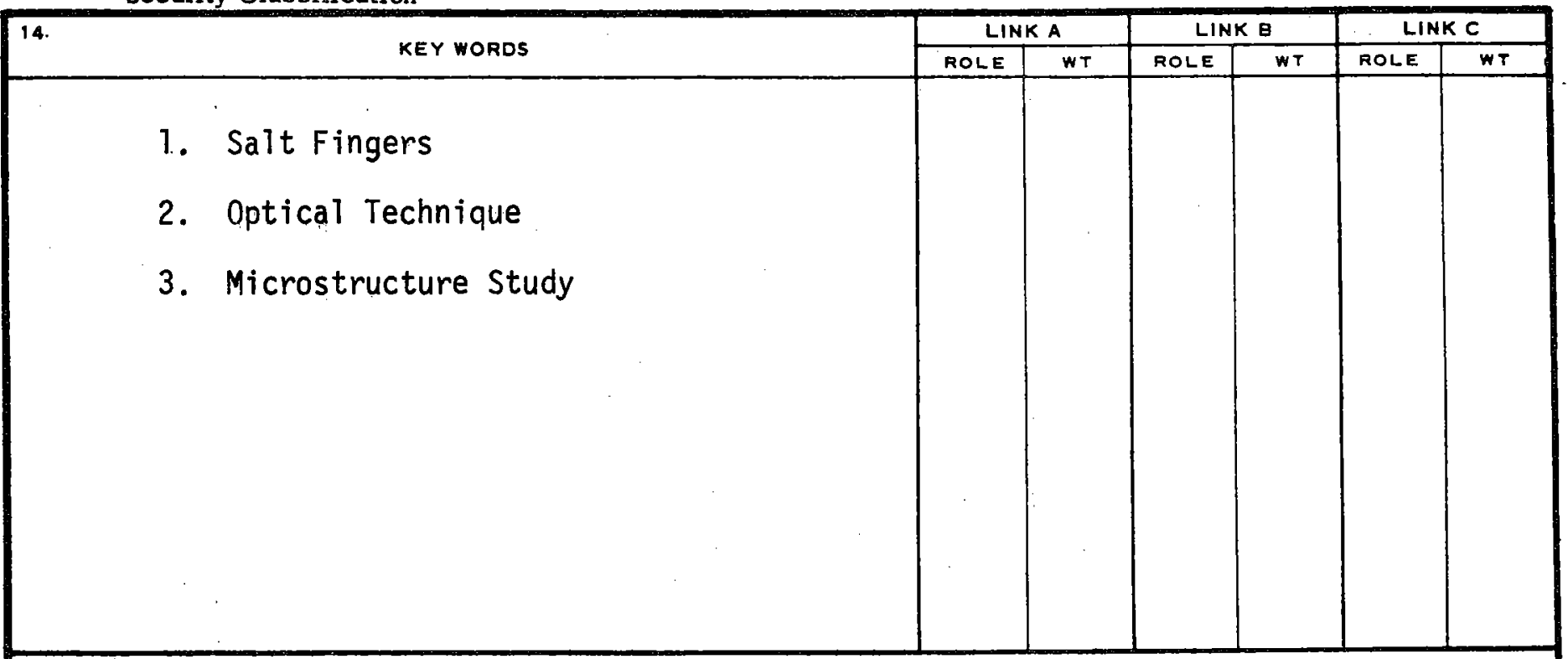

\section{INSTRUCTIONS}

1. ORIGINATING ACTIVITY: Enter the name and address of the contractor, subcontractor, grantee, Department of Defense activity or other organization (comorate author) issuing the report.

2a. REPORT SECURTY CLASSIFICATION: Enter the overall security classification of the report. Indicate whether "Restricted Data" is included Marking is to be in accord ance with appropriate security regulations.

2b. GROUP: Automatic downgrading is specified in DoD Directive 5200.10 and Armed Forces Industrlal Manual. Enter the group number. Also, when applicable, show that optional markings have been used for Group 3 and Group 4 as authorized.

3. REPORT TITLE: Enter the complete report title in all capital letters. Titles in all cases should be unclassifted. If a meaningful title cannot be selected without classification, show title classification in all capitals in parenthesis immediately following the title.

4. DESCRIPTIVE NOTES: If appropriate, enter the type of report, e.g., interim, progress, summary, annual, or final. Give the inclusive dates when a specific reporting period is covered.

5. AUTHQR(S): Enter the name(s) of author( $\theta$ ) as shown on or in the report. Ent et last name, fir st name, middle Initial. If military, show gank and branch of service. The name of the princlpal author is an ahoolute minimum requirements

6. REPORT DATE: Enter the date of the report as day, month, year; or month, year. If more than one date appears on the report, use date of publication.

7a. TOTAL NUMBER OF PAOER: The total page count should follow normal pagination procedures, $b_{1}$, enter the number of pages contaling informatlon

7b. NUMBER OF REFERENCES Enter the totel number of peferences clted in the report.

8a. CONTRACT OR ORANT NUMBER, If approprlate, onter the applicable number of the contrabt or Brant under which the report was written

8b, 8c, 8d. PROJECT NUMBER! Enter the appropriate military department Identification, such as projest number, subproject number, system numbers, task number, etc,

9a. ORIGINATOR'S REPORT NUMBER(S); Enter the offcial report number by which the document will be identifled and controlled by the originating activity. Thls number nuat be unique to this report.

9b. OTHER REPORT NUMBER(S): If the report has been assigned any other report numbers (elther by the orisinator or by the sponsot), also enter this number( $s)$.

10. AVAILABILITY/LIMITATION NOTICES: Enter any $1 \mathrm{~lm}$ itations on further dissemination of the report, other than those imposed by security classification, using standard statements such as:

(1) "Qualified requesters may obtain copies of this report from DDC."

(2) "Foreign announcement and dissemination of this report by DDC is not authorized."

(3) "U. S. Government agencies may obtain copies of this report directly from DDC. Other qual ified DDC users shall request through

(4) "U. S. military agencies may obtain copies of this report directly from DDC Other qualified users shall request through ."

(5) "All distribution of this report is controlled Qualified DDC users shall request through ."

If the report has been furnished to the Office of Technical Services, Department of Commerce, for sale to the public, indicate this fact and enter the price, if known

11. SUPPLEMENTARY NOTES: Use for additional explanatory notes.

12. SPONSORING MILITARY ACTIVITY: Enter the name of the departmental project office or laboratory sponsoring (pay ing $f \circ r$ ) the research and development. Include address.

13. ABSTRACT: Enter an abstract giving a brief and factual summary of the document indicative of the report, even though it may also appear elsewhere in the body of the technical report. If additional space is required, a continuation sheet shall be attached.

It is highly desirable that the abstract of classified reports be unclaseiflod. Each paragraph of the abstract shall end with an Indication of the military security classification of the in. formation In the paragraph, represented as (TS). (S), (C), or (U).

There is no limitation on the length of the abstract. Howover, the suggested length lo from 150 to 225 words.

14. KEY WORDS: Key words are technically meaningful terms or short phrases that characterize a report and may be used as index entrles for cataloging the report. Key words must be selected so that no security classification is required. Identiliers, ouch as equipment model designation, trade name, military project code name, geographic location, may be used as key words but will be followed by an indication of technical context. The assigament of links, rales, and weights is optional. 